Linköping Studies in Science and Technology

Thesis No. 1696

\title{
Investigation of deep levels in bulk GaN
}

\author{
Tran Thien Duc
}

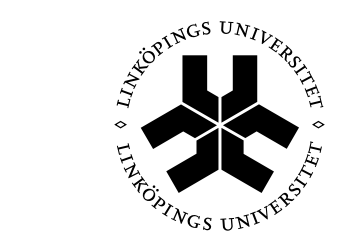

Linköping University

Semiconductor Materials Division

Department of Physics, Chemistry, and Biology (IFM)

Linköping University, SE-581 83 Linköping, Sweden

Linköping 2014 
(C) Tran Thien Duc, 2014

Printed in Sweden by LiU-Tryck 2014

ISSN 0280-7971

ISBN 978-91-7519-169-0 


\section{ABSTRACT}

The first gallium nitride $(\mathrm{GaN})$ crystal was grown by hydride vapor phase epitaxy in 1969 by Maruska and Tietjen and since then, there has been an intensive development of the field, especially after the ground breaking discoveries concerning growth and p-type doping of $\mathrm{GaN}$ done by the 2014 year Nobel Laureates in Physics, Isamu Akasaki, Hiroshi Amano and Shuji Nakamura. GaN and its alloys with In and Al belong to a semiconductor group which is referred as the III-nitrides. It has outstanding properties such as a direct wide bandgap ( $3.4 \mathrm{eV}$ for $\mathrm{GaN})$, high breakdown voltage and high electron mobility. With these properties, $\mathrm{GaN}$ is a promising material for a variety of applications in electronics and optoelectronics. The perhaps most important application is GaN-based light-emitting-diodes (LED) which can produce a highbrightness blue light. Since the bandgap of $\mathrm{GaN}$ can be controlled by alloying it with aluminium (Al) or indium (In) for a larger or smaller bandgap, respectively, $\mathrm{GaN}$ is very important for optoelectronic applications from infrared to the deep ultraviolet region. There are other semiconductors with bandgap similar to $\mathrm{GaN}$ such as $\mathrm{SiC}$, and the first commercially blue light emitting LEDs where manufactured in $\mathrm{SiC}$, however, $\mathrm{SiC}$ has an indirect bandgap with a low efficiency of emitting photons, and today, the $\mathrm{SiC}$ based LEDs have been completely replaced by the considerable more efficient $\mathrm{GaN}$ based LEDs.

One problem, which has hampered the development of GaN based devices, is the lack of native substrate of GaN. Due to that, most of the $\mathrm{GaN}$ based devices are fabricated on foreign substrates such as $\mathrm{SiC}$ or $\mathrm{Al}_{2} \mathrm{O}_{3}$. Growing on a foreign substrate results in high threading dislocation (TD) densities $\left(\sim 10^{9} \mathrm{~cm}^{-2}\right)$ and stress in the GaN layer due to lattice mismatch and difference of thermal expansion coefficient between GaN and the substrate. The high TD density and the stress influence the performance of the devices.

Another important aspect related to GaN which has attracted many studies is how defects affect the efficiency of GaN-based devices. Therefore, it is necessary to understand the properties and to identify them. When we know there properties, one can estimate how they will influence the behavior of devices, and thereby, optimize the perfor- 
mance of the device for its application. Basically, a fundamental knowledge of defect properties, and how to introduce them in a controlled manner, or to avoid them, is important in order to optimize the performance of devices. Defects can be introduced both intentionally and unintentionally into semiconductors during the growth process, during processing of the device or from the working environment, for example, devices working in a radioactive ambient are more likely to have defects induced by irradiation.

This thesis is focused on electrical characterization of defects in bulk GaN grown by halide vapor phase epitaxy (HVPE) by using deep level transient spectroscopy. Other measurement techniques like currentvoltage measurement (IV), capacitance-voltage measurement (CV) and Hall measurement were also been used. Defects related to the growth process and the polishing process are discussed in Paper 1. In Paper 2 and Paper 3, we focus on intrinsic defects in GaN introduced intentionally by electron irradiation. This type of defects are important since they can be unintentionally introduced during growth of the material, in the fabrication process of devices or if it is exposed to a radioactive environment. By electron irradiation, we can in a controlled manner introduce intrinsic defects for studies and by varying the electron beam energy and doses we can judge the nature of them. After electron irradiation, we observed several electrically active defects. These defects were characterized by DLTS to get important parameters such as activation energy, trap concentration, trap profile and capture cross-section. Especially, from temperature-dependent capacitance transient studies, we have determined the mechanism of the electron capturing process for some of them. 


\section{PREFACE}

This Licentiate Thesis is a result of three years' work during my $\mathrm{Ph}$. $\mathrm{D}$. studies in Semiconductor Materials group at Linköping University. The project was financed by Swedish Energy Agency and the Swedish Research Council (VR). The results are presented in three included papers preceded by the introduction.

Linköping, 


\section{INCLUDED PAPER}

1. Investigation of deep levels in bulk GaN material grown by halide vapor phase epitaxy

T.T. Duc, G. Pozina, E. Janzén, and C. Hemmingsson

J. Appl. Phys. 114, 153702 (2013).

2. Radiation-induced defects in GaN bulk grown by halide vapor phase epitaxy

T.T. Duc, G. Pozina, N.T. Son, E. Janzén, T. Ohshima and C. Hemmingsson

Appl. Phys. Lett. 105, 102103 (2014).

3. Capture cross-section of electron irradiation induced defect in GaN bulk grown by halide vapor phase epitaxy.

T.T. Duc, G. Pozina, N.T. Son, E. Janzén, T. Ohshima and C. Hemmingsson

In manuscript. 


\section{ACKNOWLEADGEMENTS}

I would like to show my gratitude to all the people who supported and encouraged me during the time of working and writing this thesis.

- Dr. Carl Hemmingsson - my supervisor. I would like to thank my supervisor for giving me the opportunity of studying as $\mathrm{PhD}$ in Linköping. I appreciate the time he took to share his knowledge and experience, which helped me to learn a lot of useful things for my future work.

- Prof. Erik Janzén - my second supervisor, who always supported and gave me valuable suggestion and comments to improve my knowledge.

- Prof. Nguyen Tien Son and his family - I appreciate him and his family for helping and honestly advising me when I was working and living in Sweden. I really feel as the member of his family.

- Trinh Xuan Thang - my friend who lived together with me from the beginning. He always supported and helped me in work and life as well. I feel lucky to have a friend as him.

- Ian Booker - my friend who helped me much in setup and guided me to use some systems in the lab. I learnt a lot from him, and I wish him great success and luck in the future.

- Milan Yazdanfar - my friend, thanks for the funny stories and discussions, BBQ outside and for sharing his experience in life with me.

- Xun Li - my friend, thanks for discussions about many interesting topics. I wish her having success and great luck in her life and work.

- Dinner Group (Pitsiry, Ted, Daniel, Zhafira, Martin and others) I really like our outside dinner activities. It is the time when I feel very happy to chat and cheer with my best friends.

- I also would like to thank all colleges in Semiconductor Materials Group. I feel very proud of being a member in the group. I believe that our group will develop even more in the future.

- I would like to say great thanks to my parents, my grandparents and my relatives who always believed in me and in my decisions, who never leave me when I face difficulties in my life.

- Finally, I want to thank my great love Nguyet and my dear daughter Khue (BonBon) who are the very very important people of my life. Without you, my life is nothing so thanks again for being together with me to get over the difficulties and share happiness in my life. 



\section{CONTENTS}

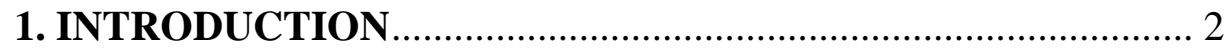

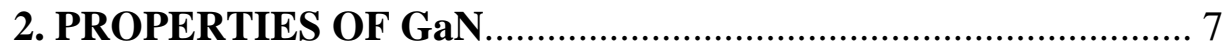

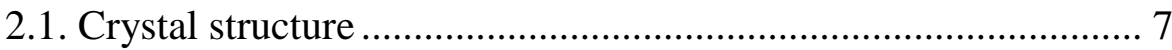

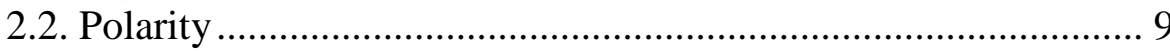

2.2.1. The spontaneous polarization field ............................... 9

2.2.1. Piezoelectric Polarity..................................................... 10

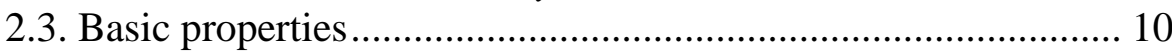

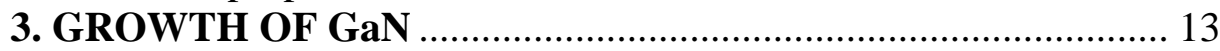

3.1. Metalorganic chemical vapor deposition (MOCVD)................. 13

3.2. Halide (Hydride) vapor phase epitaxy (HVPE) ......................... 15

4. DEEP LEVEL TRANSIENT SPECTROSCOPY ....................... 18

4.1. Metal-semiconductor junction (M-S junction) ......................... 18

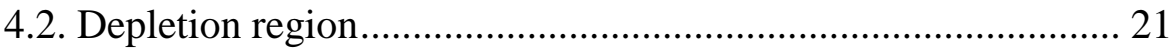

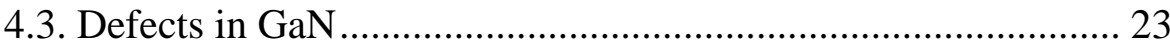

4.4. Emission and capture of charge carriers .................................. 25

4.5. Time dependence of the occupancy of traps .............................. 26

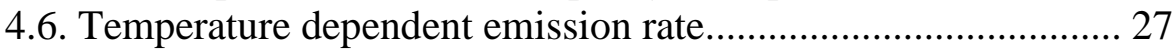

4.7. Capacitance transient spectroscopy ......................................... 29

4.8. Deep level transient spectroscopy ……....................................... 30

4.9. Output parameters of DLTS measurements ............................. 33

4.9.1. Activation energy...........................................................3

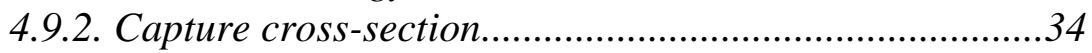

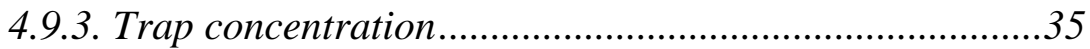

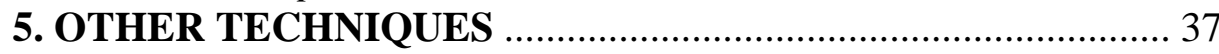

5.1. Current - voltage measurement (IV) ..................................... 37

5.2. Capacitance - voltage measurement (CV) ............................... 38

6. SUMMARY OF PAPERS ...................................................... 39

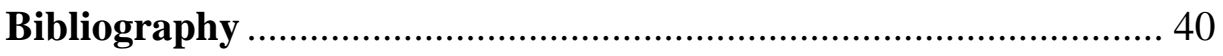




\section{INTRODUCTION}

Already in 1969, Maruska and Tietjen [1] started the development of $\mathrm{GaN}$ by successfully growing $\mathrm{GaN}$ on a sapphire substrate by Hydride (Halide) Vapor Phase Epitaxy (HVPE) method. However, due to problems in manufacturing of the material and doping, the development was hampered during the first 20 years. First in the beginning of the 90 's, the technique to make GaN p-type was developed and after that, $\mathrm{GaN}$ has been extensively studied.

$\mathrm{GaN}$ is a semiconductor consisting of an III group element $(\mathrm{Ga})$ and a $\mathrm{V}$ group element $(\mathrm{N})$. GaN has a direct and large bandgap of $3.4 \mathrm{eV}$ which depends on the temperature according to Varshni equation:

$$
E_{g}(T)=E_{g}(0)-\frac{\alpha T^{2}}{T+\beta}
$$

where $\alpha=0.909 \mathrm{meV} / \mathrm{K}$ and $\beta=830 \mathrm{~K} \mathrm{[2].}$

Moreover, the existence of AlN (a bandgap of $6.2 \mathrm{eV}$ ) and InN (a bandgap of $0.64 \mathrm{eV}$ ) enables the ability to easily control the width of the bandgap by making compound with aluminium (Al) for larger one and indium (In) for smaller one. This property makes it advantageous for optoelectronics devices working in short wavelength range [3]-[6] such as blue and ultraviolet (UV) light emitting diodes [5], laser diode [4], green light emitting devices [7] and UV photodetector [8]-[11]. In addition, GaN is also applied in the renewable energy field, particularly, making solar cells [12]-[14]. Other interesting properties are high breakdown field, high electron mobility and a high thermal conductivity. These properties opened up to new exciting applications for highfrequency and high-power devices such as transistors [8], [15]-[18], high electron mobility transistors (HEMT) [17][19] and ultrahigh power switches [8], [20]. Table 1.1 presents some basic parameters of several common semiconductors.

$\mathrm{GaN}$ is able to be grown by different methods depending on certain purpose, like metalorganic chemical vapor deposition (MOCVD) [21], molecular beam epitaxy (MBE) [22], hydride vapor phase epitaxy (HVPE) [23]-[25], high pressure solution growth (HPS) [26], [27], so- 
dium (Na) flux [28], [29], and ammonothermal method [30]. These techniques (HPS, Na flux, ammonothermal method) is used for growing thick bulk GaN while MOCVD, MBE are often used in fabricating thin layers of $\mathrm{GaN}$. The technique which has the largest growth rate is HVPE, see Table 1.2. Due to high growth rate, HVPE is the primary choice for growth of thick bulk GaN that can be used as high quality native substrate.

Table 1.1. Basic parameters for some common semiconductors are summarized from different sources [18], [31]-[38].

\begin{tabular}{|c|c|c|c|c|c|c|c|}
\hline Semiconductor & $\overline{\mathrm{Si}}$ & $\overline{\mathrm{GaAs}}$ & $\overline{\mathrm{SiC}}$ & $\overline{\mathrm{GaN}}$ & AlN & InN & Diamond \\
\hline Bandgap (eV) & 1.1 & 1.4 & 3.25 & 3.4 & 6.2 & 0.64 & $5.46-5.6$ \\
\hline $\begin{array}{l}\text { Electron Mobility at } 300 \mathrm{~K} \\
\left(\mathrm{~cm}^{2} / \mathrm{Vs}\right)\end{array}$ & 1500 & 8500 & 700 & $\begin{array}{l}1000- \\
2000\end{array}$ & 300 & 3200 & $\leq 2200$ \\
\hline $\begin{array}{l}\text { Saturated Electron Veloci- } \\
\text { ty }\left(\times 10^{7} \mathrm{~cm} / \mathrm{s}\right)\end{array}$ & 1 & 1.3 & 2 & 2.5 & & & \\
\hline $\begin{array}{l}\text { Breakdown } \\
(\mathrm{MV} / \mathrm{cm})\end{array}$ & 0.3 & 0.4 & 3 & 3.3 & $\begin{array}{l}1.2- \\
1.8\end{array}$ & 2 & $1-10$ \\
\hline Dielectric constant & 11.8 & 12.8 & 10 & $\begin{array}{l}8.9- \\
9.0\end{array}$ & 8.7 & 15.3 & 5.5 \\
\hline $\begin{array}{l}\text { Thermal } \\
(\mathrm{W} / \mathrm{cmK})\end{array}$ & 1.5 & 0.5 & 4.5 & $>1.5$ & $<2.85$ & 0.45 & $6-20$ \\
\hline
\end{tabular}

Table 1.2. Features of some common growth techniques for growing bulk GaN

\begin{tabular}{|c|c|c|c|c|}
\hline $\begin{array}{l}\text { Growth } \\
\text { Method }\end{array}$ & $\begin{array}{l}\text { High pressure } \\
\text { solution } \\
\text { (HPS)[27][26] }\end{array}$ & $\begin{array}{l}\text { Ammonothermal } \\
\text { growth }\end{array}$ & $\begin{array}{c}\text { Na-flux } \\
{[28],} \\
{[29],[39]}\end{array}$ & HVPE \\
\hline Conditions & $\begin{array}{l}\leq 2 \mathrm{GPa} \\
\leq 1700^{\circ} \mathrm{C}\end{array}$ & $\begin{array}{l}400 \mathrm{MPa} \\
600^{\circ} \mathrm{C}\end{array}$ & $\begin{array}{l}5-9.5 \mathrm{MPa} \\
600- \\
900^{\circ} \mathrm{C}\end{array}$ & $\begin{array}{l}1 \mathrm{~atm} \\
1000- \\
1100^{\circ} \mathrm{C}\end{array}$ \\
\hline Growth rate & $\begin{array}{l}0.1 \mu \mathrm{m} / \mathrm{h} \text { in c-axis } \\
0.1 \mathrm{~mm} / \mathrm{h}-\perp \mathrm{c}- \\
\text { axis }\end{array}$ & $\begin{array}{l}0.1 \mathrm{~mm} / \text { day } \\
\text { in }<0001>[30]\end{array}$ & & $\begin{array}{l}100-500 \\
\mu \mathrm{m} / \mathrm{h} \\
<0001>\end{array}$ in \\
\hline Quality & High & High & High & Normal \\
\hline Thickness & $0.1 \mathrm{~mm}$ & $\mathrm{~cm}$-scale & $<10 \mathrm{~mm}$ & mm-scale \\
\hline $\begin{array}{l}\text { Mass pro- } \\
\text { duction }\end{array}$ & $\mathrm{Bad}$ & Good & Good & Good \\
\hline Cost & Expensive & Expensive & Expensive & Cheap \\
\hline
\end{tabular}


Since there is a lack of native substrates of GaN, foreign substrates such as sapphire or $\mathrm{SiC}$ are used. Due to the difference in lattice parameters of the substrate and $\mathrm{GaN}$, the dislocation density in the material is high (in the order of $>10^{9} \mathrm{~cm}^{-2}$ for a $1 \mu \mathrm{m}$ thick layer). However, the dislocation density is dropping with thickness, and for a layer of $1 \mathrm{~mm}$, the dislocation density is $\sim 10^{6} \mathrm{~cm}^{-2}$ which is necessary for fabrication of $\mathrm{GaN}$ based lasers. Another problem related to growth of $\mathrm{GaN}$ on a foreign substrate is the difference in thermal expansion that can cause fracture in the GaN during the cooling process. Due to the high growth rate of HVPE and good control of impurities, HVPE has shown to be the technique of choice in producing $\mathrm{GaN}$ substrates commercially.

The main problems in development of GaN-based applications today are the lack of native GaN substrate and how to make p-type GaN. There is possible to grow $\mathrm{GaN}$, both from a solution or from gas phase. AMMONO company is growing and providing commercial GaN by the ammonothermal method which is a solution based technique. It gives $\mathrm{GaN}$ of high crystalline quality, nevertheless, the low growth rate and the use of high temperature and high pressure give rise to a high cost of the $\mathrm{GaN}$ substrates. Additionally, the high temperatures and the use of corrosive agents give rise to high impurity concentrations in the material. However, the dislocation densitiy of such materials is very low $\left(\sim 10^{4}\right.$ $\mathrm{cm}^{-2}$ ) which makes it interesting to be used as substrate material and recently, the AMMONO company demonstrated that ammonothermal grown GaN substrates can be used as seeds for HVPE growth[40]. Using this approach, crystalline material of high quality and low threading dislocation $\left(5 \times 10^{4} \mathrm{~cm}^{-2}\right)$ was produced. Moving on to the question of $\mathrm{p}$ doped GaN, the first p-type GaN with a hole concentration of $\sim 2 \times 10^{16}$ $\mathrm{cm}^{-3}$ was fabricated in 1989 by Amano et al. [40] in which magnesium (Mg) was used as the dopant. They discovered that $\mathrm{Mg}$ was forming a complex with $\mathrm{H}$ during cooling after growth and in order to activate the $\mathrm{Mg}$ as p-dopant the $\mathrm{GaN}$ has to be annealed in a hydrogen-free atmosphere or irradiated by electrons. Other candidates for $\mathrm{p}$-type dopant are $\mathrm{Zn}$ and $\mathrm{Cd}$, however, the activation energy is too large to be acceptable for p-type doping due to high binding energy[41], [42](Zn 0.34 eV, $\mathrm{Cd} \sim 0.55 \mathrm{eV})$. Therefore, $\mathrm{Mg}$ with its rather high thermal activation energy $(0.17 \mathrm{eV})[43]$ is the only choice for acceptor even though just few percent of $\mathrm{Mg}$ is activated at room temperature. 
Another important issue is the performance efficiency of GaN-based devices which is strongly affected by defects in the crystal. In the ideal case, we would like to grow perfect crystals with no defects. In fact, it is impossible to do. Defects always exist and they will influence of the performance of GaN-based devices. To solve this problem, understanding the origin and the properties of them is necessary. From that knowledge, we can control the defect concentration in order to optimize and improve the devices performance. The defects are often dependent on growth technique, e.g., ammonothermal grown GaN has low concentration of structural defects when compare to others but high concentration of impurities, see [44]. There are a lot of studies on defects in $\mathrm{GaN}$ grown by other techniques such as MOCVD[45]-[47], MBE[48], [49] and HVPE [50]-[52].

Defects are not only coming from the growth process but they may also appear from the working environment. Many devices are widely used in radioactive environment such as in nuclear plants and in space. In this kind of environment, defects may be introduced and consequently, change the performance of the devices. Additionally, during processing of devices, ion-implantation and plasma etching techniques are used. In these types of techniques, high-energy particles are bombarding the surface which may give rise to defects in the material. To study and understand this kind of defects, irradiation technique is often used to intentionally create intrinsic defects in the material. In irradiation technique, an electron or ion beam (He, $\mathrm{H}$ ion)[53]-[67] are employed to irradiate the sample. The two main parameters that can influence on the creation of defects are the beam energy and the dose. The higher the energy, the more degree of damage appears in the sample. However, in ion beam techniques, also the direction of the beam may influence the depth profile of damage in the crystal. This effect is often referred as the "channelling" effect.

To study defects, deep level transient spectroscopy (DLTS) which was first proposed by Lang[68] has been shown to be a powerful method. Using DLTS, one can obtain important parameters of defects such as: activation energy, capture cross-section, depth profile and defect concentration. In paper 1, the properties of defects in HVPE-grown $\mathrm{GaN}$ were studied in details by deep level transient spectroscopy (DLTS) and other electrical characterization techniques[69]. In paper 2, 
we have study electron-irradiation-induced defects in HVPE grown $\mathrm{GaN}$ and we report two new deep levels with high activation energy (D5I: $0.89 \mathrm{eV}$ and D6: $1.14 \mathrm{eV}$ ) [70]. In paper 3, the capture crosssection of eletron-irradiation-induced defects was studied by the filling pulse width method. 


\section{PROPERTIES OF GaN}

\subsection{Crystal structure}

$\mathrm{GaN}$ is a binary compound semiconductor which has two common polytypes: the zin-blende (ZB) and wurtzite (WZ), see Fig. 2(a) and (b), respectively. In $\mathrm{ZB}$ phase, $\mathrm{GaN}$ has a space group of $\mathrm{F} \overline{4} 3 \mathrm{~m}$ and each cubic unit cell consists of four $\mathrm{Ga}$ atoms and four $\mathrm{N}$ atoms. The unit cell contains two tetrahedrons in which $\mathrm{N}$ atom is surrounded by four $\mathrm{Ga}$ atoms and vice versa. The lattice constant of zinc-blende structure $\mathrm{GaN}$

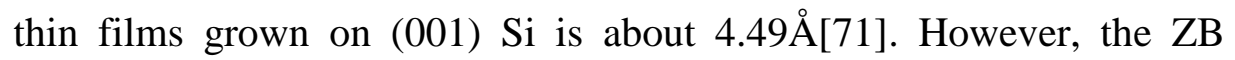
phase is not stable as the WZ phase that has a hexagonal unit cell. The ZB phase is only obtained when growing epitaxy thin films on (001) substrate. This leads to a high threading dislocation density and worsens the quality of film. In the thesis, we have studied bulk GaN with the stable WZ phase.

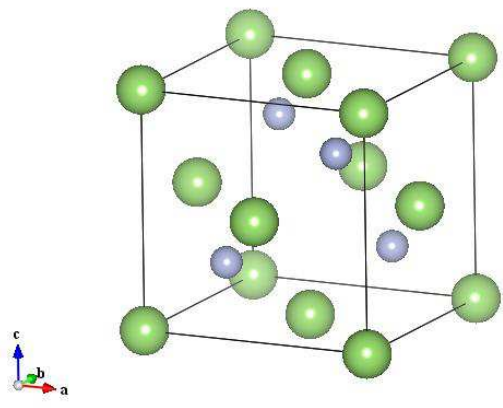

(a)

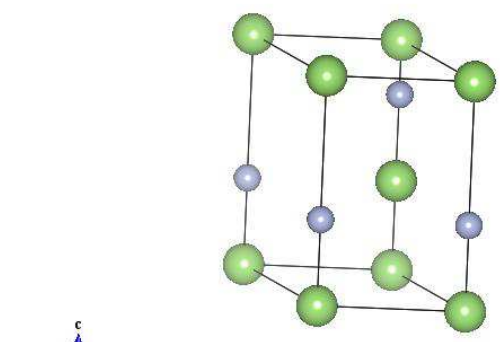

(b)

Figure 2.1. (a) zinc-blende structure and (b) wurtzite structure of GaN where Ga is illustrated as large green atom and $\mathrm{N}$ as small gray atom.

The space group for $\mathrm{WZ}$ is $\mathrm{P} 63 \mathrm{mc}$ in which the basic is comprised of two $\mathrm{Ga}$ atoms at $(0,0,0)$ and $\left(\frac{1}{3}, \frac{2}{3}, \frac{1}{2}\right)$ and two $\mathrm{N}$ atoms at $\left(0,0, \frac{3}{8}\right)$ and $\left(\frac{1}{3}, \frac{2}{3}, \frac{1}{2}+\frac{3}{8}\right)$. The WZ structure is considered as the interpenetration of two hexagonal closed packed lattices of Ga and $\mathrm{N}$ (Fig. 2.2) where the distance between $\mathrm{Ga}$ and $\mathrm{N}$ along the direction [0001] is $\frac{3}{8} c$ in ideal case. Here, $c$ is the height of a hexagonal unit cell. The lattice constants at $300 \mathrm{~K}$ are $a=3.189 \AA$ and $c=5.185 \AA$ and these constants depends 
on the temperature and the doping concentration. Depending on which kind of structure, GaN has different properties, shown in Table 2.1. GaNhas also one more polytype with rocksalt structure. However, the structure is not stable and the only condition to get this structure is under very high pressure and therefore, it has never been studied in detail.

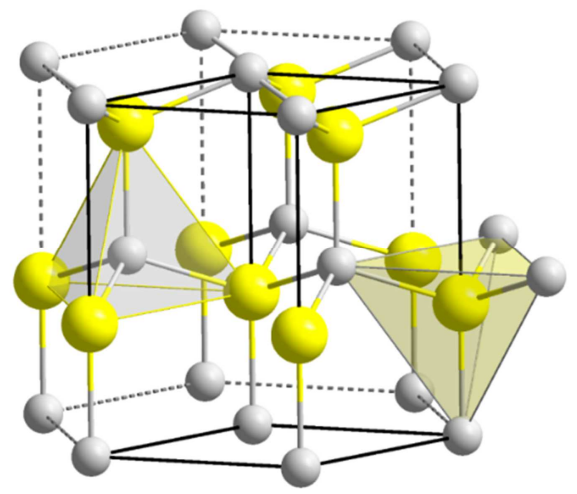

Figure 2.2. Wurtzite structure of GaN shown as two interpenetrating lattice of Ga and $\mathrm{N}$

Table 2.1. Basic properties of $\mathrm{WZ} \mathrm{GaN} \mathrm{and} \mathrm{ZB} \mathrm{GaN}[2][37]$

\begin{tabular}{|c|c|c|}
\hline Parameters & Wurtzite GaN & Zinc-blende GaN \\
\hline Lattice constant $[\AA]$ & $a=3.189, c=5.185$ & 4.5 \\
\hline The stacking order & $\begin{array}{l}\mathrm{AaBb} \text { along [0001] } \\
\text { direction }\end{array}$ & $\begin{array}{l}\text { AaBbCc along [111] } \\
\text { direction }\end{array}$ \\
\hline$P_{S P}\left(C / m^{2}\right)$ & -0.034 & \\
\hline $\begin{array}{l}\text { Effective density of states } \\
\text { in the conduction band } N_{C} \\
\left(\mathrm{~cm}^{-3}\right)\end{array}$ & $N_{C}=4.3 \times 10^{14} \times T^{\frac{3}{2}}$ & $N_{C}=2.3 \times 10^{14} \times T^{\frac{3}{2}}$ \\
\hline $\begin{array}{l}\text { Effective density of states } \\
\text { in the valence band } N_{V} \\
\left(\mathrm{~cm}^{-3}\right)\end{array}$ & $N_{V}=8.9 \times 10^{15} \times T^{\frac{3}{2}}$ & $N_{V}=8.0 \times 10^{15} \times T^{\frac{3}{2}}$ \\
\hline Effective electron mass $\mathrm{m}_{\mathrm{e}}$ & $0.20 \mathrm{~m}_{0}$ & $0.13 \mathrm{~m}_{0}$ \\
\hline $\begin{array}{l}\text { Effective mass of density } \\
\text { of state } m_{v}\end{array}$ & $1.5 \mathrm{~m}_{0}$ & $1.4 \mathrm{~m}_{0}$ \\
\hline $\begin{array}{l}\text { Breakdown field at RT } \\
\left(\mathrm{V} \mathrm{cm}^{-1}\right)\end{array}$ & $5 \times 10^{6}$ & $3.3 \div 5 \times 10^{6}$ \\
\hline Dielectric constant & 8.9 (static) & 9.7 (static) \\
\hline $\begin{array}{l}\text { Optical phonon energy } \\
(\mathrm{meV})\end{array}$ & $\begin{array}{l}5.35 \text { (high frequency) } \\
91.2\end{array}$ & $\begin{array}{c}5.3 \text { (high frequency) } \\
87.3\end{array}$ \\
\hline
\end{tabular}




\subsection{Polarity}

\subsubsection{The spontaneous polarization field}

One property of GaN that is a major obstacle for light emitting devices, but very important for fabrication of $\mathrm{AlGaN} / \mathrm{GaN}$ HEMT structure is the spontaneous polarization field. The origin of the field is the no-inversion symmetry along the c-axis ([0001] direction). The lack of inversion symmetry is shown in Fig. 2.3 where it can be seen that the crystal can be terminated either with $\mathrm{Ga}$ - atoms or $\mathrm{N}$-atoms depending on orientation. We refer the two faces as the Ga- face and the $\mathrm{N}$-face, respectively. However, one thing that needs to be noticed is that it does not mean that the surface of the Ga-face or $\mathrm{N}$-face does only consist of $\mathrm{Ga}$ or $\mathrm{N}$-atoms, respectively. The polarity is determined by the direction of bonding from $\mathrm{N}$ atom to $\mathrm{Ga}$ atom along the c-axis. When a bond forms between $\mathrm{Ga}$ and $\mathrm{N}$ atoms by sharing electrons, these electrons have a tendency to be closer to the $\mathrm{N}$ atom. Thus, the volume close to the $\mathrm{N}$ atom is more negatively charged whereas the volume around the $\mathrm{Ga}$ atom is more positively charged. This gives rise to a dipole along the Ga-N bond. This electrical field is called spontaneous polarization because it exists without the presence of strain.
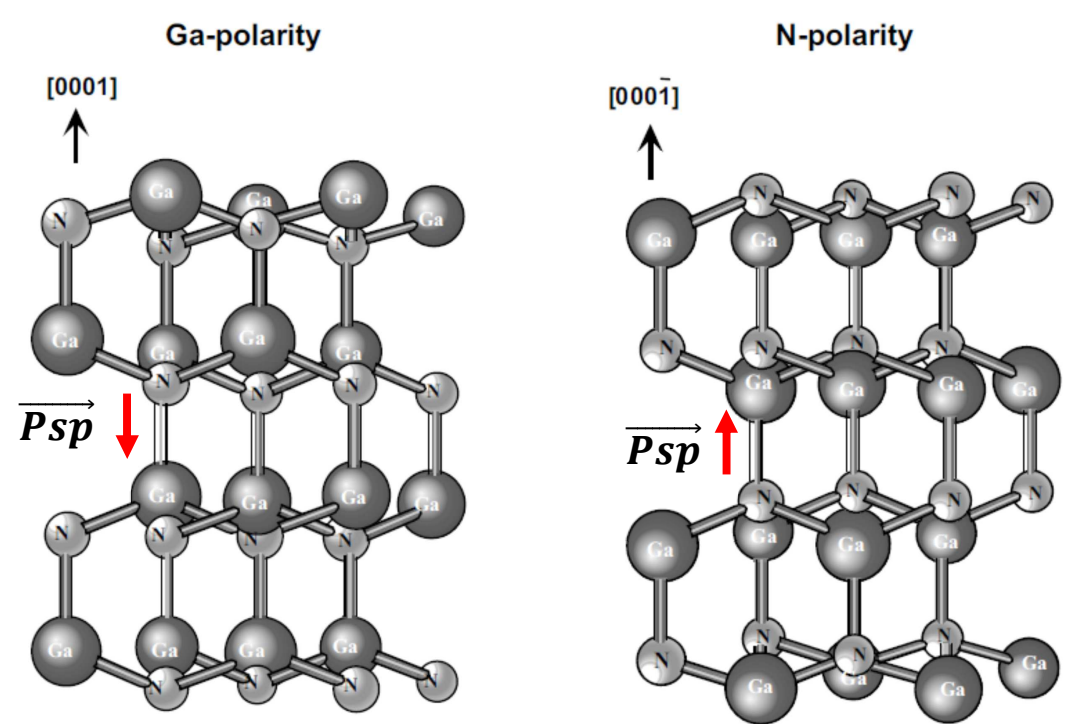

Figure 2.3. The hexagonal structure of Ga-polarity and N-polarity 


\subsubsection{Piezoelectric Polarity}

One issue when a film is grown on a foreign substrate is the lattice mismatch which leads to stress in the film. The stress deforms the structure of the film and causes a piezoelectric field that contributes to the polarization. Therefore, the total polarization field consists of two components: one from spontaneous polarization $\left(\overrightarrow{P_{S P}}\right)$ and one from piezoelectric polarization $\left(\overrightarrow{P_{P Z}}\right)$

$$
\overrightarrow{P_{T O T}}=\overrightarrow{P_{S P}}+\overrightarrow{P_{P Z}}
$$

The direction of the piezoelectric polarization depends on the relation of lattice between the film and the surface. If the film has a lattice constant smaller than the substrate, the film will be tensile strained and conversely, if the lattice constant is larger, the film will be compressively strained. The tensile strain results in a piezoelectric field vector which is parallel with the spontaneous polarization field vector while if the layer suffers from compressive strain, the vectors are antiparallel.

\subsection{Basic properties}

The most interesting property of GaN that makes it promising for optoelectronics applications, especially, blue and UV LEDs is the large direct bandgap of $3.4 \mathrm{eV}$. In LEDs, the light comes from the recombination of electrons locating around the minimum of the conduction band and holes locating around the maximum of the valence band, see Fig. 2.4. For a direct bandgap, the recombination process requires two particles: electron in the conduction band and hole in the valence band. For the indirect band, this process requires three particles: electron, hole and a phonon and that makes the probability for an electron-hole recombination significant lower and affects the efficiency of the light emitting process (Fig. 2.4). This is the reason why $\mathrm{SiC}$, which has an indirect bandgap, is less suitable as a light emitter despite that the bandgap is similar to $\mathrm{GaN}$. Another advantage of $\mathrm{GaN}$ is the possibility to control the bandgap by introducing $\mathrm{Al}$ or In which make it possible to fabricate LEDs with different wavelengths.

Other advantageous properties of $\mathrm{GaN}$ is a relatively high thermal conductivity, a high electron mobility and a high-breakdown field. The 
value of thermal conductivity that has been reported in some studies and it varies in the range of $50-250 \mathrm{~K} / \mathrm{mW}$ at room temperature [72]-[78] which is lower than the theoretically calculated value from Witek (et al.) [79]. However, this should be compared to $\mathrm{SiC}$ which has a thermal conductivity of $360 \mathrm{~K} / \mathrm{mW}$ at room temperature [31]. The high mobility and high break down field open great opportunities of fabricating highpower and high-frequency devices like photodectector, transitors and switches [8], [10], [11], [15]-[20].

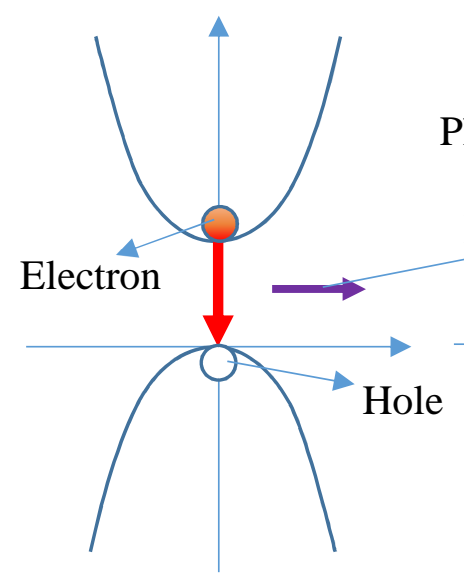

(a)

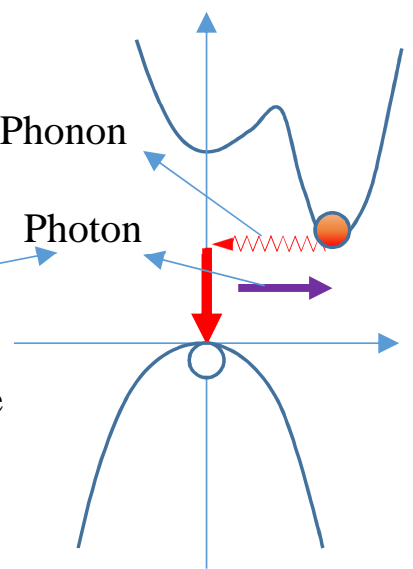

(b)

Figure 2.4. The diagram of (a) direct bandgap and (b) indirect bandgap in k-space

$\mathrm{GaN}$ is known as a compound having a high chemical stability, however, the chemical stability poses technological challenges for device processing. There have been many studies on etching of $\mathrm{GaN}$ with different etchants such as acids, bases, alkali solutions [80]-[85] at different temperatures and most of them showed an exceptional chermical stability of $\mathrm{GaN}$. In early studies by Chu et al. [83], $\mathrm{GaN}$ was found to be dissolve in sodium hydroxide $(\mathrm{NaOH})$. The main problem with this etchant is the formation of gallium hydroxide $(\mathrm{GaOH})$ which is insoluble. Later, Pankove et al. tried to address this problem by electrolytic etching technique [80]. The quality of GaN significantly affects the ability of wet etching, particularly, the low quality has the high etching rate[86]. Another interesting behavior related to wet etching is the dependence of $\mathrm{GaN}$ polarity. In Palacios et al.'s report [87], using kali hydroxide $(\mathrm{KOH})$ at $80^{\circ} \mathrm{C}$, etching was only observed on the $\mathrm{N}$-face and 
not the Ga-face. Nowaday, phosphoric acid $\left(\mathrm{H}_{3} \mathrm{PO}_{4}\right)$ [88], [89] is the most commonly used etchant in $\mathrm{GaN}$ device fabrication. The $\mathrm{H}_{3} \mathrm{PO}_{4}$ etching process is often carried out at the high temperatures $\left(\sim 190^{\circ} \mathrm{C}\right)$ with a etching rate varying in the range of $0.013-3.2 \mu \mathrm{m} / \mathrm{min}[88]$. 


\section{GROWTH OF GaN}

Since there is a lack of foreign substrates of GaN, almost all growth is done heteroepitaxially on foreign substrate materials such as sapphire, $\mathrm{SiC}$ or $\mathrm{Si}$. This gives rise to several problems. One of issues is the difference in lattice parameters between $\mathrm{GaN}$ and the substrate which give rise to a high density of threading dislocations (TD). Additionally, the difference in thermal expansion coefficients between the substrate and the film causes stress in the layer after cooling to room temperature. This stress may give rise to deformation and cracks in the film. In order to overcome these problems, various types of buffer layers are commonly used in many growth techniques.

\subsection{Metalorganic chemical vapor deposition (MOCVD)}

Nowadays, MOCVD is known as the most common method to grow device structures in the semiconductor industry. This technique is preferred in growing thin layers due to several outstanding abilities. For example, by using MOCVD one can easily control a thickness by changing some basic parameters such as temperature, pressure, flow rate of precursor, etc.. Moreover, there exist a variety of pure precursors which makes it possible to grow some different types of semiconductors or other types of material. In principle, the MOCVD growth process consists of several basic steps which are mentioned below, see Fig. 3.1.

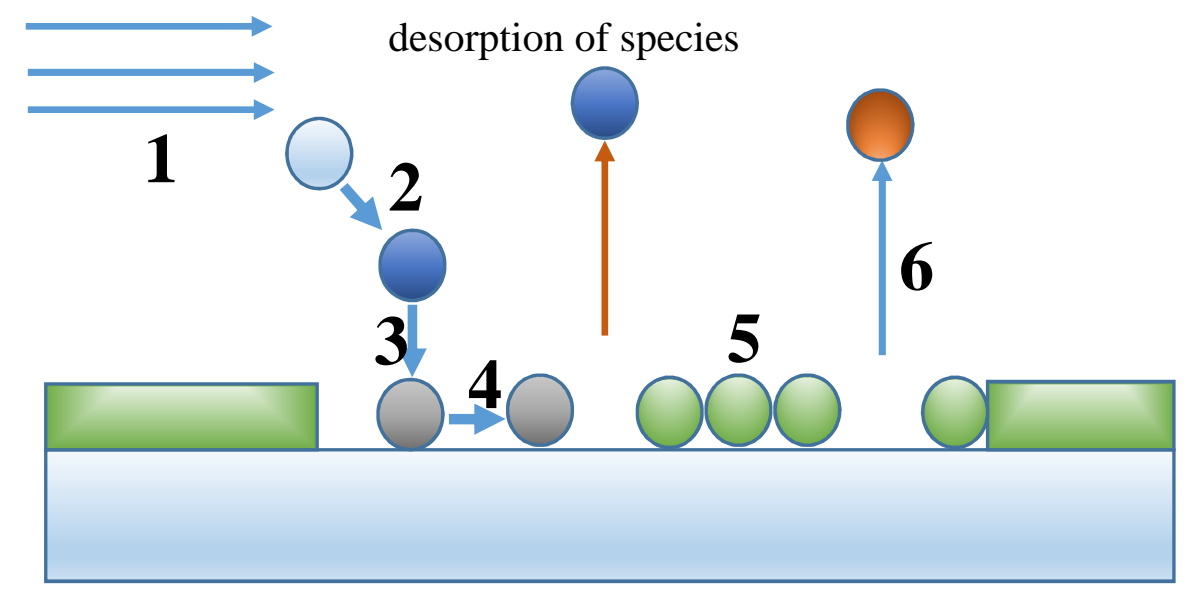

Figure 3.1. Precursor transport and reaction processes in conventional CVD 
Precursors are transported directly to the reactor's region where precursor reacts with each other. Carrier gas is used for transporting the precursors.

1. Precursors react in gas phase and create gaseous by-products and reactants

2. Reactants are transported to the substrate surface by a diffusion process.

3. On the substrate surface, the transported reactants are adsorbed

4. Surface diffusion of reactants to growth sites.

5. Growth takes place on the surface by reactions.

6. The by-products from the reactions in step 5 are desorbed then evacuated away from the reaction zone.

In 1971, Manasevit et al.[90] reported his experimental results in which he used MOCVD for growth of GaN. In his study, Manasevit et al. used two different substrates $\left(\alpha-\mathrm{Al}_{2} \mathrm{O}_{3}\right.$ and $\left.\alpha-\mathrm{SiC}\right)$ heated to $925^{\circ}$ $975^{\circ} \mathrm{C}$. Trimethylgallium (TMG) and ammonia $\left(\mathrm{NH}_{3}\right)$ were employed as sources of $\mathrm{Ga}$ and $\mathrm{N}$. However, the quality of $\mathrm{GaN}$ film at that time was not good due to an un-optimized growth process and low purity of the precursors.

The quality of GaN depends strongly on the quality of precursors and the substrates. Due to low cost, sapphire has been widely used as substrate even though the lattice mismatch is quite high. To deal with this problem, Amano and Akasaki [91] found a new method in which AlN was used as a buffer layer. This method has been widely and commercially used in growth of GaN until now. The buffer layer of GaN or AlN plays a role as a nucleation layer that absorbs the strain appearing during the growth process. The buffer layer has a thickness of few tens of $\mathrm{nm}$ and is often fabricated at low temperature in case of GaN.

In case of doping, MOCVD enables the possibility to easily dope the material by adding a organic compounds as a dopant source. In doping of $\mathrm{GaN}, \mathrm{Mg}$ is used to make the material p-type and $\mathrm{Si}$ is used for ntype doping. In MOCVD system, bis-cyclopentadienylmagnesium $\left(\mathrm{Cp}_{2} \mathrm{Mg}\right)$ and silane $\left(\mathrm{SiH}_{4}\right)$ are commonly used as a source of $\mathrm{Mg}$ and $\mathrm{Si}$, respectively. These two compounds are transported to the substrate 
by a carrier gas of $\mathrm{H}_{2}, \mathrm{~N}_{2}$ or a mixture of $\mathrm{H}_{2} / \mathrm{N}_{2}$. Fig. 3.2 shows a diagram of MOCVD system using for doping $\mathrm{Si}$ or $\mathrm{Mg}$.

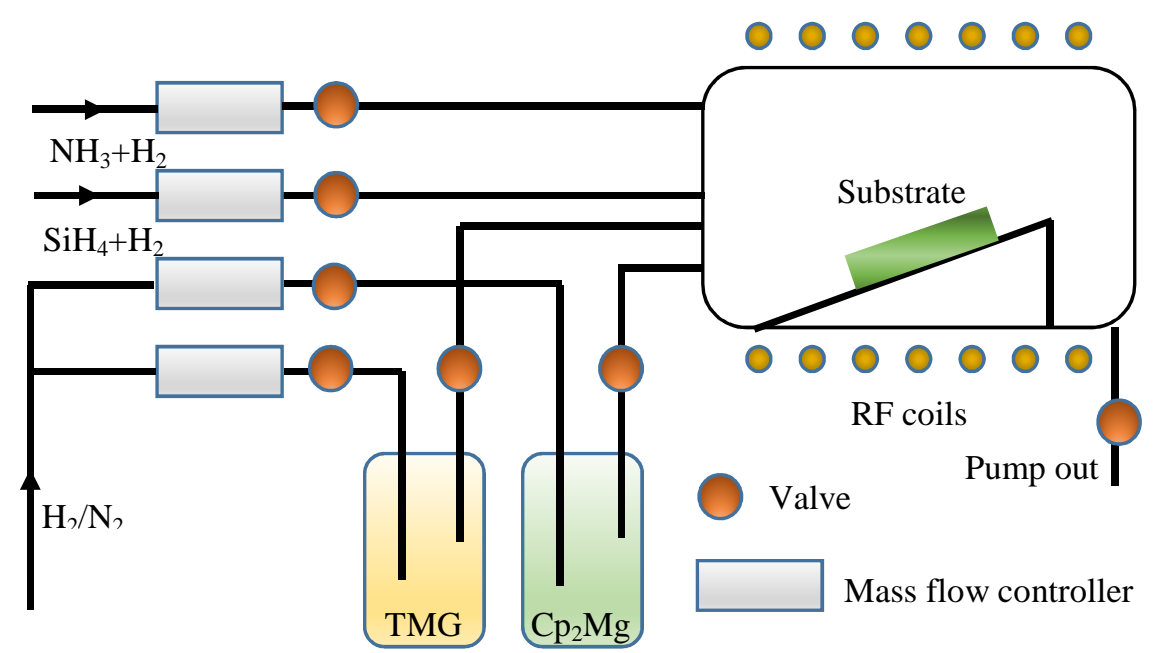

Figure 3.2. Schematic diagram of the MOCVD process which $\mathrm{SiH}_{4}$ and $\mathrm{Cp}_{2} \mathrm{Mg}$ are used for growth of n-type and p-type GaN

\subsection{Halide (Hydride) vapor phase epitaxy (HVPE)}

HVPE has been used for growth of $\mathrm{GaN}$ for 45 years. The first successful growth of single crystal GaN was done by Maruska in 1969[1]. The characteristic of this technique is a high growth rate (100-500 $\mu \mathrm{m} /$ hour along <0001> direction)[92] [92] which makes it as the preferred choice for growing thick GaN bulk material.

Many studies showed that high-quality GaN can be obtained by using HVPE in combination with other techniques. By using MOCVD grown $\mathrm{GaN}$ as starting layer, the initial growth is facilated or by using ammonothermal growth substrate, the crystal quality is very high from the beginning of growth. . The quality of GaN crystal can be also improved by growing a low-temperature GaN buffer layer which is expected to reduce the propagation of threading dislocations from the $\mathrm{GaN}$ and the substrate interface[23].

All samples used for study in Paper 1-3 are thick free-standing GaN grown in a vertical hot wall HVPE reactor described in Fig. 3.3. The 
chamber is made of quartz and divided into two zones (source zone and growth zone). In Linköping University's vertical HVPE reactor, the source zone which is heated by a resistive heater is at the lower part of the reactor. In the source zone, gallium chloride is formed by flowing $\mathrm{HCl}$ through a boat containing liquid $\mathrm{Ga}$. The temperature of the source zone is often kept $\sim 800-900^{\circ} \mathrm{C}$ at which the chemical reactions between $\mathrm{Ga}$ and $\mathrm{HCl}$ occurs as following:

$$
\begin{aligned}
& G a(l)+H C l(g)=G a C l(g)+\frac{1}{2} H_{2}(g) \\
& G a(l)+2 H C l(g)=G_{a C l}(g)+H_{2}(g) \\
& G a(l)+3 H C l(g)=G a C l_{3}(g)+\frac{3}{2} H_{2}(g) \\
& 2 G a C l_{3}(g)=\left(G a C l_{3}\right)_{2}(g)
\end{aligned}
$$

The source zone's temperature decides which reaction should be predominant. By thermodynamic calculation, the reaction (3.1) is predominant when the temperature is above $500^{\circ} \mathrm{C}$ [93]. By keeping the temperature around $800-900^{\circ} \mathrm{C}$, the efficiency of reaction (1) is very high[94]. This means that almost all $\mathrm{HCl}$ introduced into the $\mathrm{Ga}$ boat reacts with Ga.

When gaseous gallium chloride is formed, gallium chloride is transported to the growth zone through the quartz tube by a carrier gas of $\mathrm{H}_{2}$ or $\mathrm{H}_{2} / \mathrm{N}_{2}$. In the growth zone, a mixture of ammonia and $\mathrm{H}_{2}$ is transported into the reaction region where ammonia reacts with gallium chloride to form $\mathrm{GaN}$ according to the below reaction:

$$
\operatorname{GaCl}(g)+\mathrm{NH}_{3}(g)=\mathrm{GaN}+\mathrm{HCl}+\mathrm{H}_{2}
$$

One issue needs to address is the parasitic growth because the outlets of ammonia and gallium chloride are quite close. Consequently, ammonia easily reacts with gallium chloride to form $\mathrm{GaN}$ which deposits in the precursors inlet. If the GaN grown too thick, it will prevent precursors to enter the reactor. To address this problem, a flow of light gas $\left(\mathrm{H}_{2}\right.$ or $\mathrm{H}_{2} / \mathrm{N}_{2}$ ) is introduced between the ammonia tube and the gallium chloride, depicted in Fig. 3.3. This flow will prevent the ammonia gas from mixing with the gallium chloride before they arrive to the substrate. 


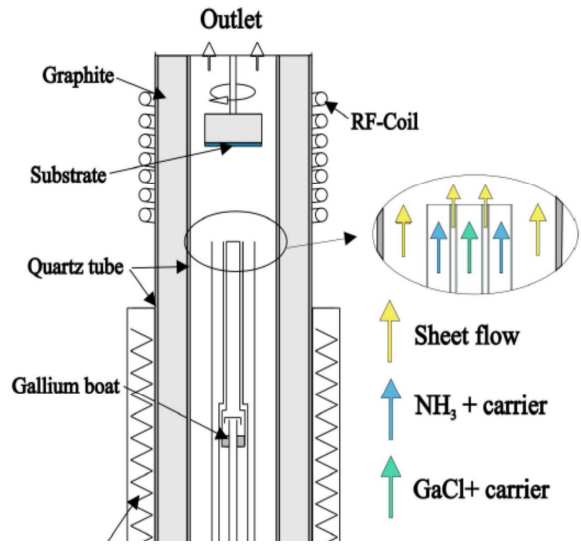

Figure 3.3. Schematic diagram of a vertical HVPE reactor for growth of GaN [93] (move down) 


\section{DEEP LEVEL TRANSIENT SPECTROSCOPY}

\subsection{Metal-semiconductor junction (M-S junction)}

In semiconductor devices, the M-S junction plays a very important role as the bridge between the semiconductor component and an external voltage source. Depending on the properties of the semiconductor and the metal, we can form a rectifying Schottky junction that only conducts current in one direction or a linear Ohmic junction where the current is linearly dependent on the applied voltage. In order to fabricate a Schottky diode, we need both a Schottky and an Ohmic junction, see Fig. 4.1. In the thesis, all samples used for electrical characterization are prepared as Schottky diodes to which consist of two kinds of MS junction. Since we are only using n-type $\mathrm{GaN}$, we will restrict the discussion to n-type Schottky diodes. Therefore, this part will focus on the characteristics of the n-type Schottky diode which is fabricated by making a contact between metal and n-type GaN semiconductor, as shown in Fig. 4.1. The applied voltage $V_{a}$ can be negative or positive depending on working condition.

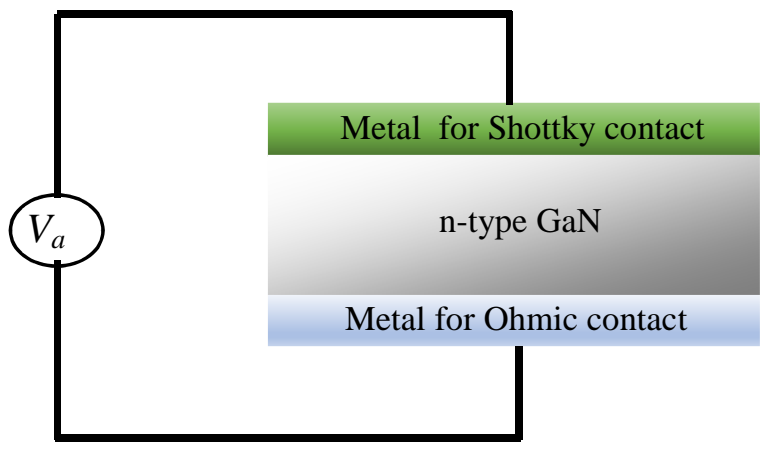

Figure 4.1. Structure of GaN Schottky diode

To understand the principle of forming barrier between semiconductor and metal, it is convenient to use an energy band diagram. Fig. 4.2(a) shows the flat band diagrams of metal and an n-type semiconductor. There are some important notations needed to be described here. $E_{F m}$ and $E_{F s}$ are the Fermi level of the metal and semiconductor, respectively. $\phi_{m}, \phi_{s}$ are the work function of the metal and the semiconductor, respectively. The work function is the potential between the Fermi level and the vacuum level $\left(E_{v a c}\right) \cdot \chi$ is the electron affinity (EA) defining the energy needed to remove a electron in the conductor band edge $\left(E_{C}\right)$ to 
the vacuum level. Depending on the work function $\phi_{m}$ of the metal and the electron affinity $\chi$ of the semiconductor, the M-S junction can behave as a Schottky or an Ohmic junction. For GaN, the EA is determined by theoretical calculation to about $1.44 \mathrm{eV}$ [95] and $1.88 \mathrm{eV}$ [96]. However, these values are much lower than the experimental value which is about $4.1 \mathrm{eV}$ at room temperature [37]. Fig. 4.2.(b) shows the flat band diagram after forming a contact between metal and n-type semiconductor. Observe that the thermal equilibrium condition is not considered in this figure. Here is $\phi_{B}$ the barrier height which is the difference between the metal work function and the affinity of the semiconductor:

$$
\phi_{B}=\phi_{m}-\chi
$$

The barrier height is the potential between the Fermi level of the metal and the conduction band edge. Therefore, the value of the barrier height is dependent on the metal. The barrier height of some metals which is commonly used for making Schottky diode on n-type $\mathrm{GaN}$ is shown in Table 4.1.

To form a Schottky contact on n-type GaN, there are two requirements that need to be fulfilled:

- The doping concentration is not too high

- The work function of the metal has to be greater than the one of the n-type semiconductor.

Table 4.1. Summary some important parameters of metal commonly used for making contact with n-type GaN[97]-[99]

\begin{tabular}{cccccccc}
\hline \hline Metal & $\mathrm{Au}$ & $\mathrm{Ni}$ & $\mathrm{Pt}$ & $\mathrm{Ti}$ & $\mathrm{Al}$ & $\mathrm{In}$ & $\mathrm{Ag}$ \\
\hline $\begin{array}{c}\text { Work } \\
\text { function }\end{array}$ & 5.1 & 5.15 & 5.65 & 4.33 & 4.08 & 4.09 & 4.26 \\
$\begin{array}{c}\text { Barrier } \\
\text { height }\end{array}$ & $0.87-0.98$ & $0.95-1.13$ & $1.01-1.16$ & - & - & - & - \\
Contact & Shottky & Shottky & Shottky & Ohmic & Ohmic & Ohmic & Ohmic \\
\hline \hline
\end{tabular}



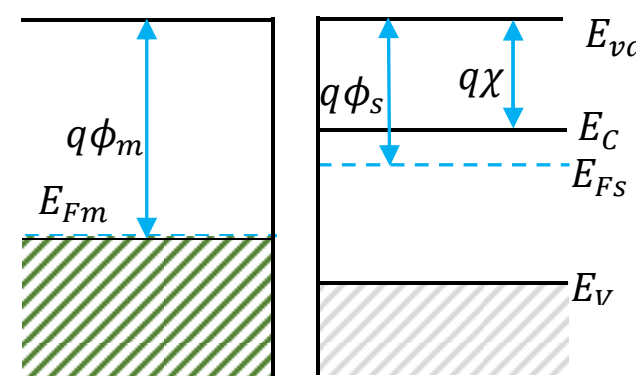

(a)

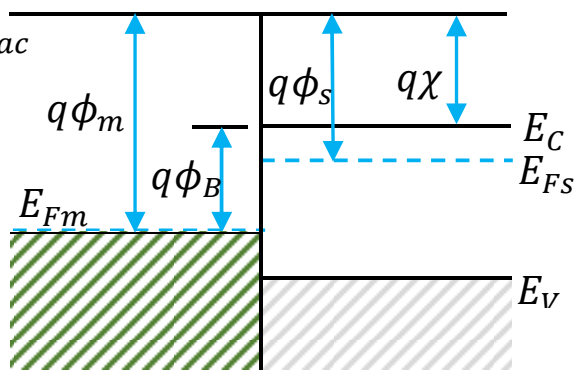

(b)

Figure 4.2. Flat band digrams of the metal and semiconductor in the case of no contact (a) and making a contact (b).

In Fig. 4.3.(a), the thermal equilibrium condition is taken into account and we obtain a thermal equilibrium diagram in which a bending of the band is observed. When a metal having a higher work function touches a semiconductor, higher energy electrons in the semiconductor will diffuse through the junction to the metal and create a diffusion current. This leaves positive ionized donors in the semiconductor which results in forming an electric field. This field will create a drift current. The diffusion of electrons continues until the electric field is high enough to prevent electrons in the semiconductor from further diffusion. Thus, the diffusion current is equal to the drift current and the Fermi levels in the metal and the semiconductor are equal in thermal equilibrium. At this time, a barrier for the carrier is formed to hinder futher electron diffusion between the two regions, as depicted in Fig. 4.3(a).

The term $V_{i}$ in Fig. 4.3 is called the built-in potential which is the energy needed to be supplied to an electron in the semiconductor to surmount the potential barrier. The built-in potential for a metalsemiconductor junction in this case is obtained by the equation below [100]:

$$
V_{i}=\phi_{M}-\chi-\frac{E_{C}-E_{f s}}{q}=\phi_{B}-\frac{k T}{q} \ln \frac{N_{C}}{N_{d}}
$$

where $k$ is the Boltzmann constant, $q$ the charge of the carrier, $T$ the temperature, $N_{d}$ the donor concentration and $N_{C}$ is the effective density of states in the conduction band which is calculated by [101]: 


$$
N_{C}=2\left[\frac{2 \pi m_{e}^{*} k T}{h^{2}}\right]^{3 / 2}
$$

where $h$ is Plank constant and $m_{e}$ is the effective electron mass. For nGaN Schottky, it is convenient to use the approximate equation [102]:

$$
V_{i}=\frac{1}{3}\left(3.503+\frac{5.08 \times 10^{-4} T^{2}}{T-996}\right)(\mathrm{eV})
$$

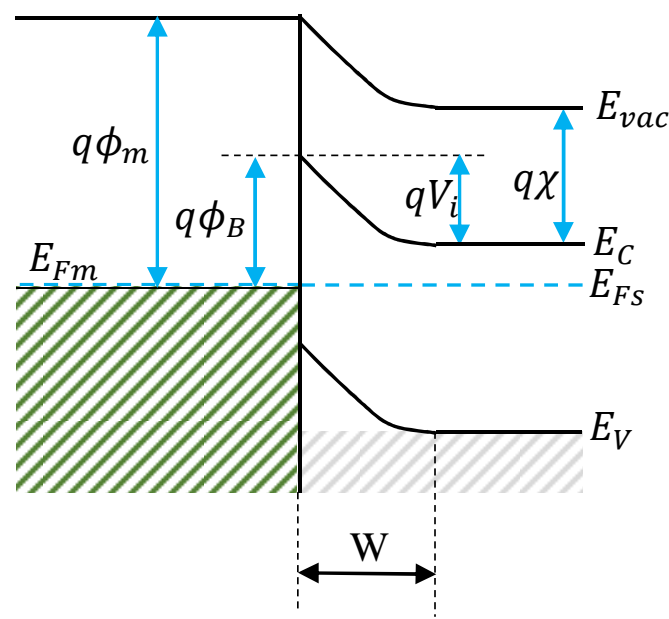

(a)

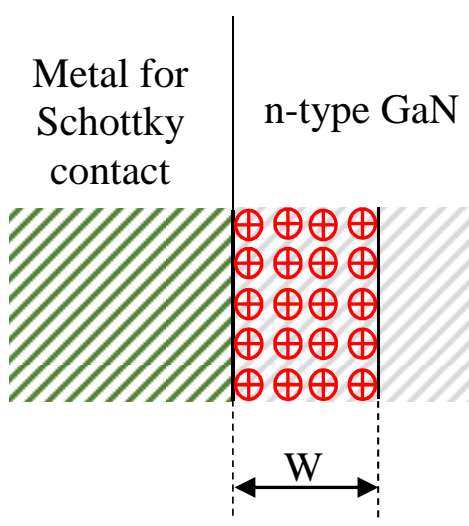

(b)

Figure 4.3. The thermal equilibrium diagram (a) and the positive ionized donor region (b) for a n-type Schottky diode

\subsection{Depletion region}

In the thermal equilibrium state, there is a region formed in the semiconductor in which there is no free carrier. This region is called the depletion region. In principle, the depletion region extends to the metal region, however, the extension into the metal is negligible due to the much greater electron concentration than the doping concentration in the semiconductor [103]. The depletion width $W$ can be calculated by using Poisson's equation and for the case of a Schottky contact it is given by: 


$$
W=\sqrt{\frac{2 \varepsilon_{r} \varepsilon_{0} V_{i}}{q N_{d}}}=\sqrt{\frac{2 \varepsilon V_{i}}{q N_{d}}}
$$

where $\varepsilon, \varepsilon_{r}, \varepsilon_{0}$ are the permittivity, the relative permittivity (also called electric constant, $\left.\varepsilon_{r}(\mathrm{GaN})=8.9\right)$, the vacuum permittivity $\left(\varepsilon_{0}=\right.$ $\left.8.86 \times 10^{-12} \mathrm{~F} / \mathrm{m}\right)$, respectively; $q=1.6 \times 10^{-19} \mathrm{C}$ is the elementary charge; $N_{d}$ is the donor concentration and $V_{i}$ is the built-in potential.

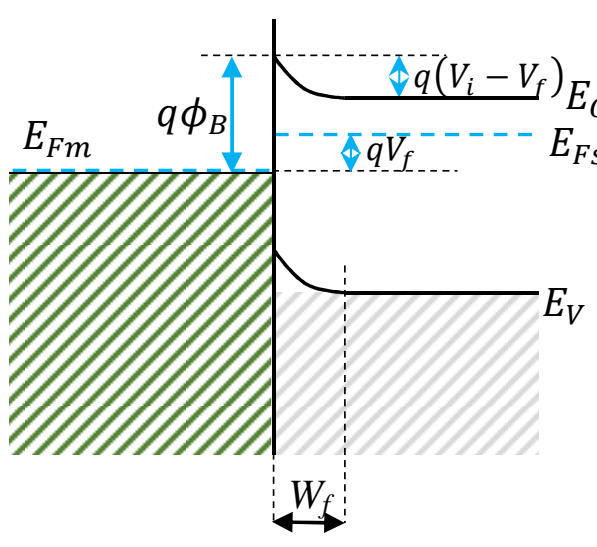

(a)

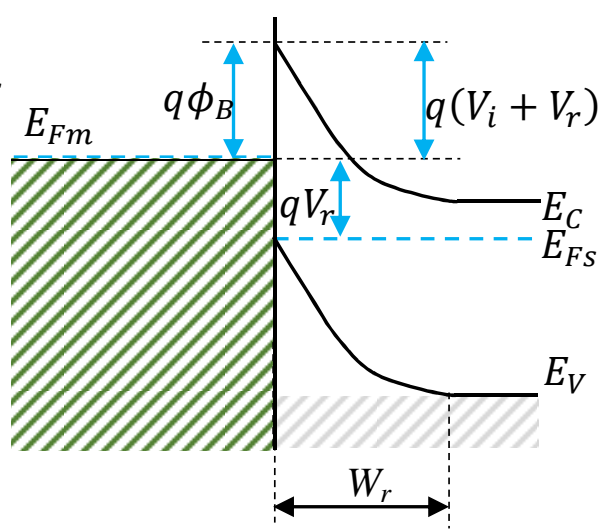

(b)

Figure 4.4. Band diagram of n-type Schottky contact under a forward bias (a) and a reverse bias (b)

Another important behavior of the depletion region is the dependence on the applied voltage. The depletion width widens when a reverse bias applies to Schottky diode and shortens in case of a forward bias. Fig. 4.4 illustrates the behavior of the bending band when applying a forward bias and a reverse bias. The depletion width in the cases of a forward bias and a reverse bias is calculated by the equation (4.6) and (4.7), respectively.

$$
W_{f}=\sqrt{\frac{2 \varepsilon_{r} \varepsilon_{0}\left(V_{i}-V_{f}\right)}{q N_{d}}}
$$




$$
W_{r}=\sqrt{\frac{2 \varepsilon_{r} \varepsilon_{0}\left(V_{i}+V_{r}\right)}{q N_{d}}}
$$

When working with characterization techniques like capacitancevoltage measurement (CV), deep level transient spectroscopy (DLTS) which will be mentioned in later, we indirectly measure the width $W$ of the depletion region by measuring the capacitance.. From the capacitance, one can obtain some important parameters such as the depth profile of doping concentration or defect concentration. The equation for calculating the capacitance $C$ of the depletion region is given below [103] in which the depletion region is considered as the capacitance of two parallel plates with area A:

$$
C=\frac{\varepsilon_{r} \varepsilon_{0} A}{W}
$$

\subsection{Defects in GaN}

In all crystals, we have defects and $\mathrm{GaN}$ is no exception. Some of them are introduced intentionally since we want to change the property of the material (i.e. by doping), while others may be introduced unintentionally during growth, by the ambient or during processing of the material. Fig. 4.5 depicts some common defects in semiconductor crystal: (1) vacancy, (2) self-interstitial, (3) foreign interstitial, (4) foreign substitutional, (5) stacking fault, (6) dislocation, (7) precipitate, (8) interstitial type dislocation loop, (9) vacancy type dislocation loop. Defects (1)-(4) and (5)-(9) are called point defects and line defects, respectively.

Referring to point defects, it is necessary to distinguish two definitions: intrinsic defects and extrinsic defects. For intrinsic point defects, a host atom at a certain position is missing and leaves a vacancy behind or a host atom occupies an interstitial site to form self-interstitial defect. For extrinsic point defects, the origin of this defect relates to foreign atoms which can take a lattice or interstitial site. Foreign atoms which can be introduced unintentionally or intentionally into the semiconductor are called impurities or solutes, respectively. 
(3) (4)

(1)

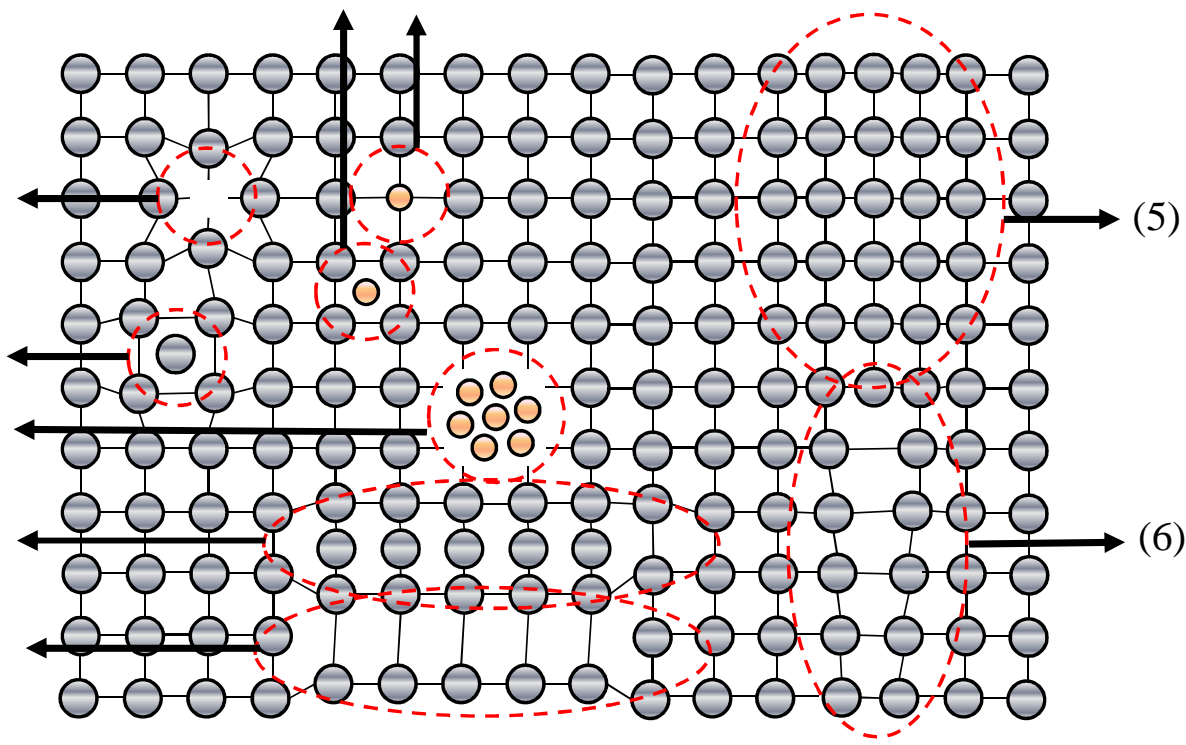

Figure 4.5. Defects in semiconductor crystal (based on [107][115])

For $\mathrm{GaN}$, these defects are commonly introduced in the growth process, during device processing and by the working environment. Defects affect strongly the performance of GaN-based devices, and therefore, it is essential to understand the properties and the origin of defects which opens up the ability to control the behavior of devices. The thesis will focus on intrinsic defects which may be introduced during growth, device processing or by the working environment.

By introducing defects in the crystal, energy levels which are localized in the proximity to the defect are formed. If the energy level is close to the edge of the conduction or valence band, defects are refereed as shallow. These defects are used to control the concentration of charge carriers and can be introduced by doping with a suitable element (e.g. Si for n-type $\mathrm{GaN}, \mathrm{Mg}$ for p-type $\mathrm{GaN}$ ). In the case of defects with energy levels locating deeply in the band gap (>100 meV), they are called deep level defects. Fig. 4.6 shows the presence of deep levels in the semiconductor band structure. Deep levels in the upper half of the band gap often have a higher probability of capturing electrons in the conduction band whereas deep levels in the lower half of the band gap have a higher probability of capturing holes in the valence band. 


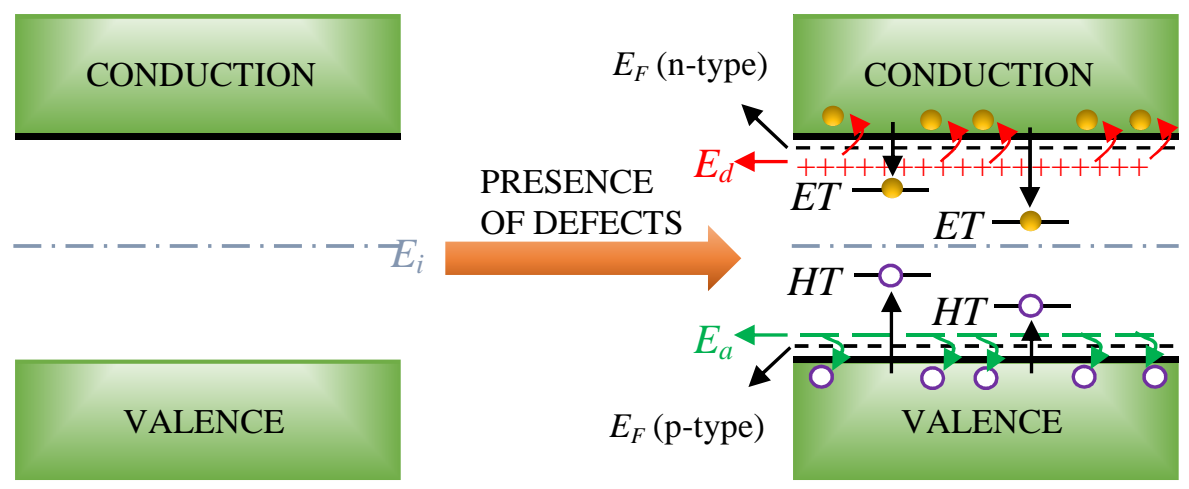

Figure 4.6. Band structure diagram of the undoped semiconductor and the doped semiconductor with a presence of deep levels caused by defects where $E_{i}$ is the intrinsic Fermi level, $E_{F}$ is the Fermi level of the $n$-type and $p$-type semiconductor, $E_{d}$ and $E_{a}$ are the level of donors and acceptors, ET is the electron trap, $H T$ is the hole trap.

\subsection{Emission and capture of charge carriers}

The emission and capture process of charge carriers can be described by the Shockley-Read-Hall statistics [104], [105]. There are four processes which can happen as a deep level is introduced into the band gap: (a) the capture of electrons from the conduction band, (b) the emission of electrons from the trap center, (c) the emission of holes to the valence band or the emission of electrons from the valence band to the trap center, (d) the capture of holes from the valence band. Fig. 4.7 describes the emission and capture of electron and hole by a deep level in the band gap in which $n$ and $p$ are the concentrations of electrons and holes in the conduction band and valence band, respectively, $p_{T}$ and $n_{T}$ are the concentration of the empty trap and the filled traps, $c_{n} n$ and $c_{p} p$ are the capture rate of electron and hole, $e_{n, p}$ are the emission rate of electron and hole. These terms of $c_{n}$ and $c_{p}$ are called the capture coefficient which has the unit of $\mathrm{cm}^{3} / \mathrm{s}$ and is defined by:

$$
c_{n, p}=\sigma_{n, p}\left\langle v_{t h}\right\rangle
$$

where $v_{t h}$ is the thermal velocity of electron or hole, $\sigma_{n, p}$ is the capture cross-section of the deep level. 
By combining the four capture and emission processes, we can form some important specific cases. A combination of process (a) and (b) or process (c) and (d) is the trap case. A generation event appears when the process (b) occurs followed by the process (d). The third case is the recombination in which the process (c) occurs after the process (a), or vice versa. If the recombination and the generation occur together, the impurity is viewed as a G-R center (Generation-Recombination center). It is important to distinguish the behavior of an impurity if it acts as a trap or a G-R center. For the trap case, just one band (conduction band or valence band) and the impurity participated while two bands and the impurity for the case of the G-R center.

(a)

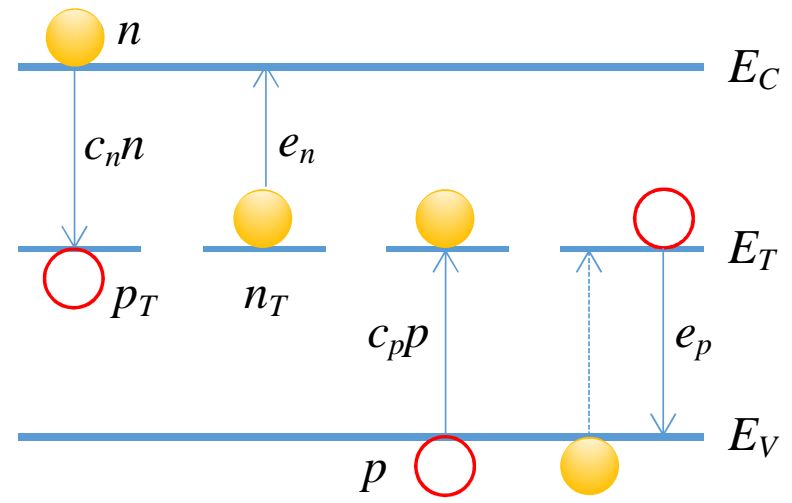

Figure 4.7. Emission and capture processes of electron and hole at the trap level locating into the band gap of the semiconductor.

\subsection{Time dependence of the occupancy of traps}

Emission and capture lead to a change of the carrier concentration ( $n$, $p)$ and the concentration of filled trap centers $\left(n_{T}\right)$. Therefore, it is important to determine the relation between $n, p$ and $n_{T}$ and consider the case of how the electron concentration in the conduction band changes. The number of electrons can increase by electron emission from the trap level or decreases by electron capture (case b and a, respectively, in Fig. 4.7). The net change of electrons in the conduction band is the differ- 
ence between these two processes. Thus, the rate equation can be written as:

$$
\frac{d n}{d t}=(b)-(a)=e_{n} n_{T}-c_{n} n p_{T}
$$

In analogue with Eq. 4.10, the rate equation for holes has a similar form and is given by the net change of holes in the valence band:

$$
\frac{d p}{d t}=(d)-(c)=e_{p} p_{T}-c_{p} p n_{T}
$$

To determine how the concentration of filled traps is changing with time $\left(\frac{d n_{T}}{d t}\right)$, we can use the relations how electron and hole concentration is changing with time, (Eq. (4.10) and Eq. (4.11), respectively). The concentration of filled traps decreases with an increase of the electron concentration which is related to the emission process of electron from the trap center. Opposite to that, when the trap center emits a hole to the valence band, it leaves a filled trap center behind. For this reason, the rate of change of the filled trap center is given by the difference between these two processes:

$$
\begin{array}{r}
\frac{d n_{T}}{d t}=\frac{d p}{d t}-\frac{d n}{d t}=e_{p} p_{T}-c_{p} p n_{T}-e_{n} n_{T}+c_{n} n p_{T} \\
=\left(e_{p}+c_{n} n\right)\left(N_{T}-n_{T}\right)-\left(c_{p} p+e_{n}\right) n_{T}
\end{array}
$$

where $N_{T}=p_{T}+n_{T}$ is the total defect concentration.

\subsection{Temperature dependent emission rate}

Most of the papers in the thesis are focused on electron traps in ntype $\mathrm{GaN}$, for this purpose, it is useful to formulate the electron emission rate from Eq. (4.12). Actually, it is not easy to solve Eq. (4.12) without doing simplifications. First, electron traps are considered in thermal equilibrium at which the principle of detailed balance is used. Therefore, there is no change in the number of electron traps in thermal equilibrium because the capture rate of electron (hole) must be equal to the emission rate of electron (hole). Thus, we have: 


$$
\begin{aligned}
& e_{p}\left(N_{T}-n_{T}\right)=c_{p} p n_{T} \\
& e_{n} n_{T}=c_{n} n\left(N_{T}-n_{T}\right)
\end{aligned}
$$

From that, the ratio of $n_{T} / N_{T}$ can be expressed as the function of capture rate and emission rate as:

$$
\frac{n_{T}}{N_{T}}=\frac{e_{p}}{e_{p}+c_{p} p}=\frac{c_{n} n}{e_{n}+c_{n} n}
$$

Using Fermi-Dirac distribution function[103], the degree of occupancy of traps is given:

$$
\frac{n_{T}}{N_{T}}=\left[1+\frac{g_{0}}{g_{1}} \exp \left(\frac{E_{T}-E_{F}}{k T}\right)\right]^{-1}
$$

Where $g_{0}, g_{1}$ are the degeneracy factors of the deep level when being empty or occupied by an electron, respectively. From Eq. 4.15 and 4.16, the electron emission rate is derived:

$$
e_{n}=c_{n} n \frac{g_{0}}{g_{1}} \exp \left(\frac{E_{T}-E_{F}}{k T}\right)
$$

The electron concentration in the conduction band is expressed by [106]:

$$
n=N_{C} \exp \left(-\frac{E_{C}-E_{F}}{k T}\right)
$$

where $N_{C}$ is the effective density of states in the conduction band and valence band:

$$
N_{C}=2 M_{C}\left(\frac{2 \pi m_{e}^{*} k_{B} T}{h^{2}}\right)^{1 / 2}
$$

where $M_{C}$ is the number of conduction band minima of the semiconductor (for wurzite $\mathrm{GaN} M_{C}=1$ ), $m_{e}^{*}$ is the effective mass of electron. Substituting $c_{n}$ in Eq. 4.17 by $\sigma_{n} v_{t h}$ in Eq. 4.9 , the electron emission rate can be rewritten as: 


$$
e_{n}=\sigma_{n}\left\langle v_{t h}\right\rangle \frac{g_{0}}{g_{1}} N_{C} \exp \left(-\frac{E_{C}-E_{T}}{k T}\right)
$$

where $\left\langle v_{t h}\right\rangle$ is the rms thermal velocity of electron and hole:

$$
\left\langle v_{n, p}\right\rangle=\left(\frac{3 k_{B} T}{m_{e}^{*}}\right)^{1 / 2}
$$

Combination of Eq. 4.19, 4.20, 4.21, it is convenient to rewrite the emission rate as following:

$$
e_{n}=\frac{g_{0}}{g_{1}} \sigma_{n} \gamma T^{2} \exp \left(-\frac{E_{C}-E_{T}}{k T}\right)
$$

where $\gamma=2 \sqrt{3}\left(\frac{2 \pi}{h^{2}}\right)^{\frac{3}{2}} m_{n}^{*} k^{2} M_{C}$. Eq. 4.22 is "the heart" of DLTS from which the activation energy and the capture cross-section can be determined.

\subsection{Capacitance transient spectroscopy}

The basic principle of capacitance transient spectroscopy is based on monitoring a time-dependent change of the charge density in the space charge region of a diode. The width of the space-charge region $W$ is dependent on the charge density and, therefore, the change can be recorded as a change of the diode capacitance since the width is related to the capacitance according to Eq. 4.8. The thermal emission of trapped charge carriers in the space-charge region make the capacitance of a p-n or Schottky diode change and it results in a capacitance transient that is recorded and analyzed to obtain important information of the trap such as activation energy, capture cross-section and trap concentration.

The principle is shown in details in Fig. 4.8. Firstly, (1) a fixed reverse bias $V_{r}$ is applied to the diode in order to remove electrons from traps in the depletion region. Next, (2) a voltage pulse, named a filling pulse $V_{f}$, is introduced to fill all traps below the Fermi level. After the pulse ends, (3) the reverse bias is restored. The free electrons are rapidly swept out from the depletion region while the removals of trapped electrons are governed by the thermal emission from the trap level. During 
the emission process, the capacitance of the depletion region changes as the function of time according to [107]:

$$
C(t)=C_{r}\left[1-\frac{n_{T 0}}{2 N_{D}} \exp \left(-\frac{t}{\tau_{e}}\right)\right]
$$

Where $n_{T 0}$ is the density of filled traps at $t=0, C_{r}$ the capacitance of the diode when all traps are empty at $V_{r}, \tau_{e}$ is the emission time constant, and $\tau_{e}=\frac{1}{e_{n}}$. Eq. 4.23 describes the capacitance transient, and is used to determine important defect parameters.
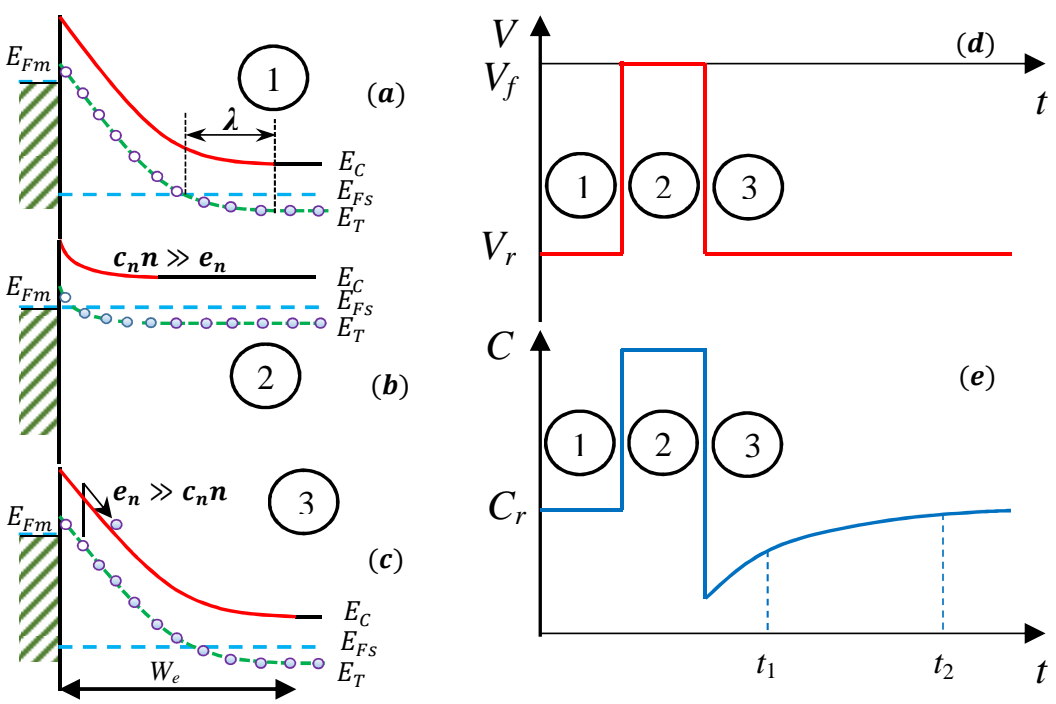

Figure 4.8. Band diagram of a Schottky diode for (a) reverse bias, (b) zero bias, (c) reverse bias at $\mathrm{t}=0$, the applied voltage on a Schottky diode (c) and the capacitance behaviour of a Schottky diode (e)

\subsection{Deep level transient spectroscopy}

Deep level transient spectroscopy which was introduced by Lang[68] in 1974 is the most powerful and widely used capacitance transient technique in characterization of electrically active traps in semiconductors. In DLTS, which is a correlation technique, we are multiplying the capacitance transient with reference signal known as the weighting function $\left(F_{\text {corr }}(t)\right)$ and the resulting signal is integrated. 


$$
S=\frac{1}{T} \int_{o}^{T} C(t) F_{c o r r}(t) d t
$$

where $T$ is the period of the weighting function. By doing this the signal-to-noise can be improved and we can determine traps with low concentrations. The simplest case of weighting function has the form:

$$
F_{\text {corr }}(t)=\delta\left(t-t_{1}\right)-\delta\left(t-t_{2}\right)
$$

where $\delta\left(t-t_{i}\right)$ is the Kronecker delta and $t_{1}$ and $t_{2}$ two different time points. Solving Eq. 4.24 with the weighting function of Eq. 4.25 and noticing that $T=t_{2}-t_{1}$, the DLTS output signal is:

$$
S=C\left(t_{2}\right)-C\left(t_{1}\right)
$$

The two different time points define something that is called the rate window. The emission rate from the trap is temperature dependent, and therefore, the time constant of the capacitance transient. When the emission rate corresponds to the rate window, the DLTS signal $S(T)$ will show a peak related to that trap as shown in Fig. 4.9. Actually, the rate window contains information about the emission rate which is chosen as a reference value.

When substituting $C(t)$ in Eq. 4.26 by Eq. 4.23 , the DLTS output is:

$$
S(t)=C_{r} \frac{n_{T 0}}{2 N_{D}}\left[\exp \left(-\frac{t_{2}}{\tau_{e}}\right)-\exp \left(-\frac{t_{1}}{\tau_{e}}\right)\right]
$$

To get the condition for the maximum peak, differentiation of $S(t)$ with respect to $\tau_{e}$ is used:

$$
\frac{d S(t)}{d \tau_{e}}=C_{r} \frac{n_{T 0}}{2 N_{D} \tau_{e}^{2}}\left[t_{2} \exp \left(-\frac{t_{2}}{\tau_{e}}\right)-t_{1} \exp \left(-\frac{t_{1}}{\tau_{e}}\right)\right]=0
$$

Solving Eq. 4.28, the relationship between $\tau_{e(\max )}$ and the rate window is obtained: 


$$
\tau_{e(\max )}=\frac{t_{1}-t_{2}}{\ln \left(\frac{t_{1}}{t_{2}}\right)}
$$

Therefore, by choosing the rate window, it is possible to determine the emission rate through the time constant. Each emission rate corresponds to a certain temperature at which the DLTS peak occurs. By varying the sampling time $t_{1}$ and $t_{2}$ so that the reference constant time changes, a series of DLTS spectra are obtained in which the DLTS peak move to the left (lower temperature) or the right (higher temperature), corresponding to an increase or decrease of the reference constant time, respectively. This is useful for identify the activation energy of the trap as we will show later.

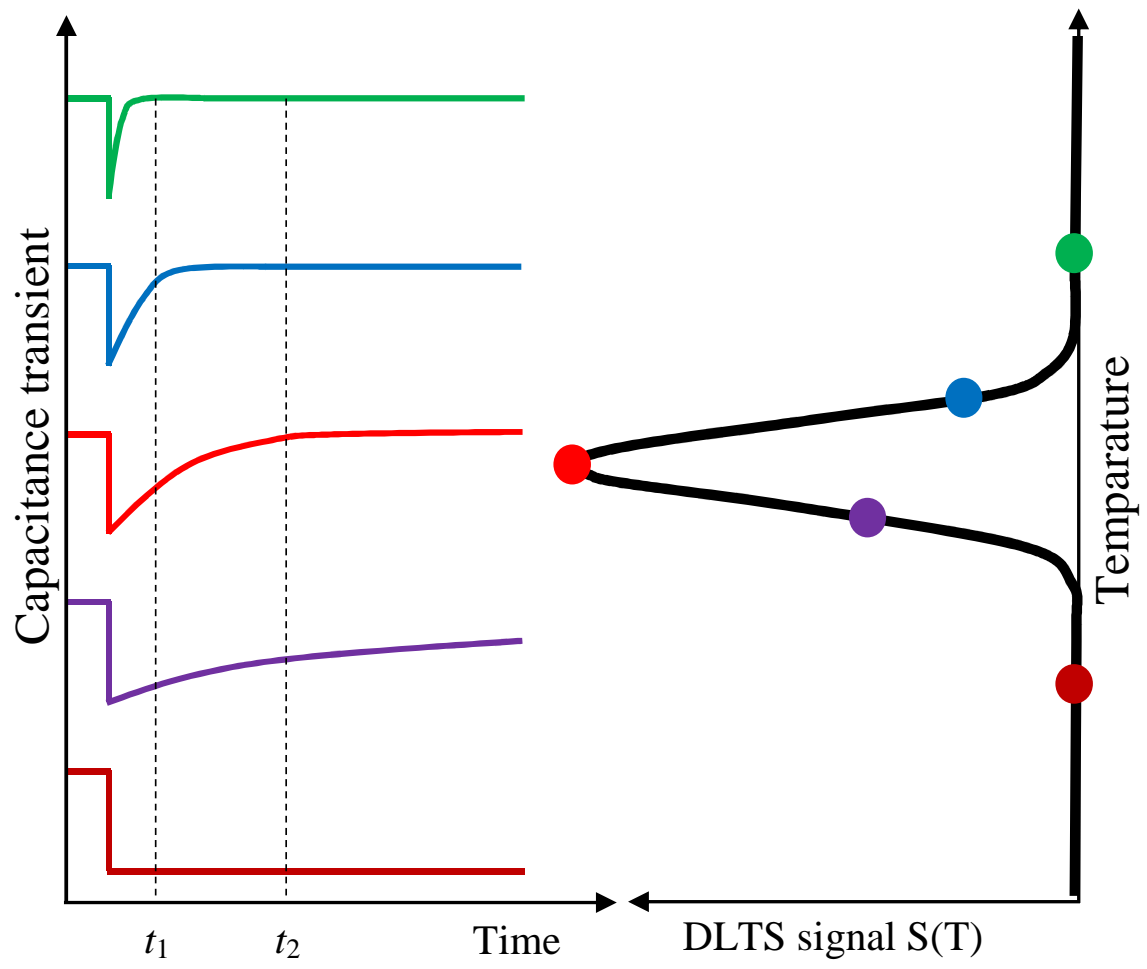

Figure 4.9. The DLTS spectrum obtained from analysis of the capacitance transients 


\subsection{Output parameters of DLTS measurements}

\subsubsection{Activation energy}

When characterizing defects, one important parameter is the activation energy, which is the energy needed to empty the trap. The way of determining the activation energy is based on Eq. 4.22. After taking the natural logarithm of the expression can be written as:

$$
\ln \left(\frac{e_{n}}{T^{2}}\right)=\ln \left(\frac{g_{0}}{g_{1}} \sigma_{n} \gamma\right)-\frac{E_{C}-E_{T}}{k T}=\ln \left(\frac{g_{0}}{g_{1}} \sigma_{n} \gamma\right)-\frac{E_{A}}{k T}
$$

From Eq. 4.30, it is possible to extract the activation energy by using a semi-logarithmic plot of $\ln \left(\frac{e_{n}}{T^{2}}\right)$ versus $\left(\frac{1000}{T}\right)$, named an Arrhenius plot. To construct the Arrhenius plot, a series of DLTS spectra are obtained by changing the window rate. An example is shown in Fig. 4.10(a). Next, the temperature of each peak minima/maxima and the corresponding emission rate is plotted in an Arrhenius plot, shown in Fig. 4.10(b). By linear fitting using Eq. 4.30, we can determine the activation energy $E_{A}$ and a rough estimate of the capture cross-section $\sigma_{n}$.

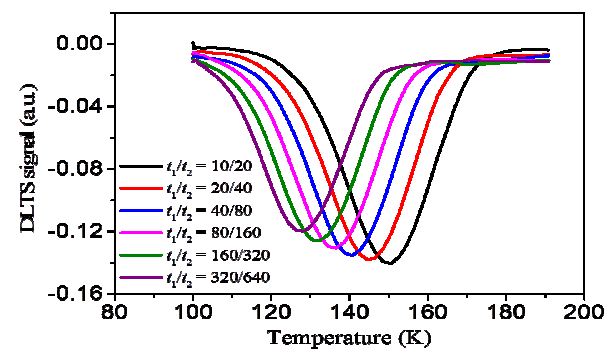

(a)

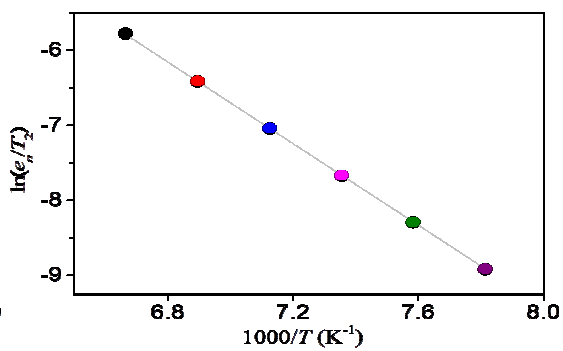

(b)

Figure 4.10. A series of the DLTS spectra corresponding to different window rates (a) and the Arrhenius plot derived from the DLTS spectra. 


\subsubsection{Capture cross-section}

The relationship between the emission rate and the capture crosssection in Eq. 4.30 is commonly used to determine capture crosssection. By finding the intercept of the Arrhenius plot and the vertical axis, the capture cross-section is obtained. However, the capture crosssection derived from Eq. 4.30 is not very accurate because it does not take into account of the dependence of the emission rate on the Gibb energy. Thus, the intercept point actually gives a value of $\sigma_{n, \text { effective }}=$ $\sigma_{n} \exp \left(\frac{\Delta S}{k}\right)$ which means that the value from Eq. 4.30 is only a rough estimate of the capture cross-section. To get the accurate capture crosssection, the value from Eq. 4.30 has to be divided by the term of $\exp \left(\frac{\Delta S}{k}\right)$. In many cases, the capture cross-section is dependent on temperature which makes the situation even more complex. In many capturing processes the capture cross-section can be described by the relationship below [108]:

$$
\sigma_{n}=\sigma_{T \rightarrow \infty} \exp \left(-\frac{E_{a \sigma}}{k T}\right)
$$

where $\sigma_{T \rightarrow \infty}$ is the capture cross-section when the temperature goes to infinity and $E_{a \sigma}$ is the capture cross-section barrier. Consequently, Eq. 4.22 can be rewritten in the form which the dependence of the emission rate on the Gibbs free energy and the temperature, more details of description is presented in Ref. [107]:

$$
e_{n}=\frac{g_{0}}{g_{1}} \sigma_{T \rightarrow \infty} \exp \left(\frac{\Delta S}{k}\right) T^{2} \exp \left(-\frac{\Delta H+E_{a \sigma}}{k T}\right)
$$

where $\Delta S$ and $\Delta H$ are the entropy and the enthalpy, respectively.

Even if the method using the intercept point for evaluation does not give the exact value, however, it has been widely used in many reports for estimating a rough value of $\sigma_{n}$.

In order to get a more accurate estimate of $\sigma_{n}$, a technique suggested by Criado et. al. [109] can be used. In this technique, the DLTS peak 
amplitude is measured as the function of different filling pulse width. By using very short filling pulses, all traps will not have time to capture carrier and we will therefore only get a DLTS signal from filled traps. By plotting the DLTS amplitude as a function of the filling pulse width, we can determine the capture cross-section. Depending on which kinds of defect (point defect or extended defect), the relationship between the DLTS signal and the filling pulse width is written as below:

For point defect[69],[110], [111]:

$$
S_{\text {peak }}\left(t_{f}\right)=S_{1}\left[1-\exp \left(-\sigma_{n} n\left\langle v_{t h}\right\rangle t_{f}\right)\right]+S_{2} \ln \left(S_{3} t_{f}\right)
$$

where $S_{\text {peak }}\left(t_{f}\right)$ is the DLTS peak corresponding to the filling pulse width $t_{f}, S_{1}, S_{2}$ and $S_{3}$ are the parameters in which $S_{1}$ is related to the trap concentration, $S_{2}$ and $S_{3}$ are related to the free carrier tail. These three parameters are determined by fitting the function of $S_{\text {peak }}$ versus $t_{f}$ by using Eq. (4.32).

For extended defect[69][110], [112]:

$$
S_{\text {peak }}\left(t_{f}\right)=S_{4} \ln \left(t_{f}\right)
$$

where $S_{4}$ is determined by fitting

\subsubsection{Trap concentration}

Another important parameter is the trap concentration. This information is quite straight forward to obtain from the DLTS spectrum since the peak amplitude of the defect is proportional to the trap concentration. However, the DLTS technique is just suitable for the trap concentration much less than the donor concentration. The trap concentration can be calculated by [107]:

$$
N_{T}=\frac{\left|S_{\text {peak }}\right|}{C_{r}} \frac{2 r^{\frac{r}{r-1}}}{1-r} N_{d}
$$

Where $S_{\text {peak }}$ is the amplitude of the DLTS peak and $r=t_{2} / t_{1}$. The expression is evaluated from Eq. 4.27 and Eq. 4.29. Observe that Eq. 
4.35 is only valid if the filling pulse is long enough to fill all defects in the investigated part of the depletion region.

However, the trap concentration can be affected by the free carrier tail which is located at the edge of the depletion region, where the free carrier concentration is gradually decreasing. This can be considered as a free carrier tail into the depletion region. This region extends a distance of $\lambda$ from the edge of the depletion region to the point at which the Fermi level crosses the trap level $\left(E_{F}=E_{T}\right)$, see in Fig. 4.8(a). The width of this region in steady state is given by [113]:

$$
\lambda=\sqrt{\frac{2 \varepsilon_{r} \varepsilon_{0}}{q^{2} N_{d}}\left(E_{F}-E_{T}\right)}
$$

It is obvious that the transition region is independent with the applied voltage which means this region, for a certain trap level and a uniform donor concentration, is constant whether the diode is under a reverse or forward bias. In the case of low electric field (a reverse bias is small) where the depletion width is a little larger than the transition region, it will affect the accuracy of DLTS measurement, particularly, the trap concentration calculated from a DLTS spectrum is not correct. In that case, it is necessary to add a $\lambda$-related correction. However, the transition region can be neglected when the depletion width in the case of a high electric field is much larger than the transition region.

In the case of taking into account of the influence of the free charge carrier tail, the equation for calculating the trap concentration needs to be modified. If we assume that the depletion widths caused by a reverse bias and a filling voltage are $W_{r}$ and $W_{f}$, respectively, only the traps in the region of $\left(W_{r}-\lambda\right)$ and $\left(W_{f}-\lambda\right)$ are monitored by the DLTS method. Thus, the real trap concentration now is given by:

$$
N_{T, \text { real }}=\frac{W_{r}^{2}}{\left(W_{r}-\lambda\right)^{2}-\left(W_{f}-\lambda\right)^{2}} N_{T}
$$

All the trap concentrations in Paper $\mathbf{1}$ is corrected by Eq. 4.37. 


\section{OTHER TECHNIQUES}

\subsection{Current - voltage measurement (IV)}

The DLTS technique requires a good quality of Schottky diode which has a low leakage current. This is due to the strong influence of the leakage current on the capacitance measurement which can lead to serious errors in analysis of the DLTS spectrum[114]. Some problems related to leakage current are reduction of the peak amplitude, a shift of the peak position and broadening of peaks which may give rise to wrong trap concentration, activation energy. To assess the property of the Schottky diode, IV is widely used. All samples in the thesis were characterized by IV measurement to make sure that the leakage current is under a value of $10 \mu \mathrm{A}$ [103].

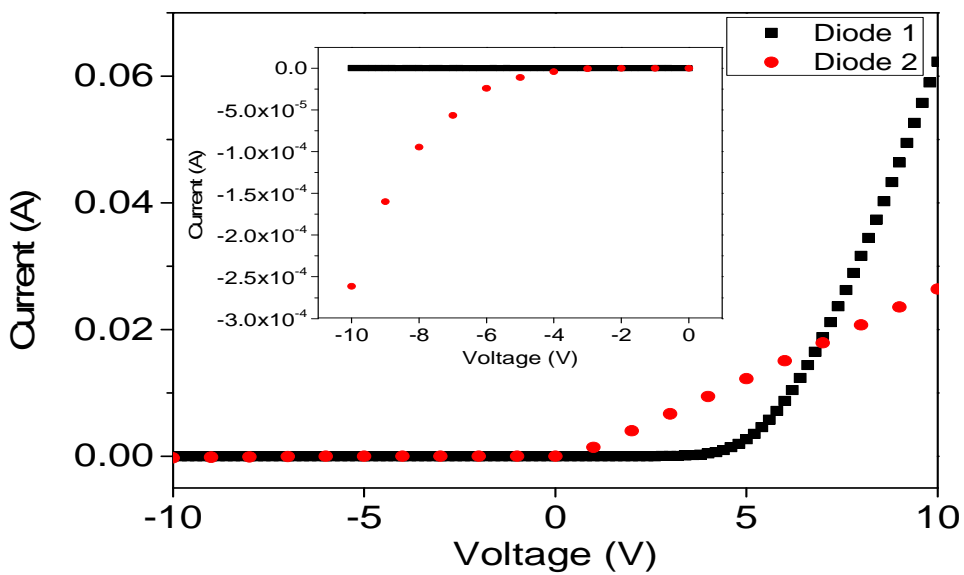

Figure 5.1. Current-voltage measurement of two different Schottky diodes in the range of $-10 \mathrm{~V}$ to $10 \mathrm{~V}$, the insert shows the scaled up range of $-10 \mathrm{~V}$ to $0 \mathrm{~V}$.

Fig. 5.1 shows the IV data of two Schottky diodes which demonstrates rectifying properties. However, only one of the diodes fulfills the requirement for carrying out DLTS measurements (diode 1). Diode 2 is not good for DLTS measurements since the leakage current at $-10 \mathrm{~V}$ is too high $(>250 \mu \mathrm{A})$. This can seriously affect the accuracy of the parameters obtained from DLTS. 


\subsection{Capacitance - voltage measurement (CV)}

As mentioned in section 4.7.3, the donor concentration is needed for calculation of the trap concentration. To get the donor concentration, it is quite convenient and simple to use a $\mathrm{CV}$ measurement. The principle of this measurement relies on the relationship between the depletion region capacitance and the donor concentration which is shown below [103]:

$$
\frac{1}{C^{2}}=\frac{2 V}{A^{2} \varepsilon_{r} \varepsilon_{o} q N_{d}}=\frac{2\left(V_{r}+V_{i}\right)}{A^{2} \varepsilon_{r} \varepsilon_{o} q N_{d}}
$$

where $A$ is the area of the contact, $C$ is the capacitance, $N_{d}$ is the net donor concentration, $\varepsilon_{r}, \varepsilon_{o}$ are the relative permittivity (also called electric constant, $\left.\varepsilon_{r}(G a N)=8.9\right)$, the vacuum permittivity $\left(\varepsilon_{0}=8.86 \times\right.$ $10^{-12} \mathrm{~F} / \mathrm{m}$ ), respectively, $V$ is total voltage, $V_{r}$ is the reverse bias, $V_{i}$ is the built-in potential and $q$ is the elementary charge. From Eq. 5.1, it is apparent that the slope of the $1 / C^{2}$ versus $V$ plot can provide the donor concentration. The built-in potential is also obtained from this plot by extrapolating the line to the crossing point of the voltage axis. 


\section{SUMMARY OF PAPERS}

Paper 1: Deep levels in free-standing GaN grown by halide vapor phase epitaxy were electrically characterized by using deep level transient spectroscopy (DLTS). Six electron traps with activation energy derived from the Arrhenius plot were observed in the DLTS spectrum: $\mathrm{E}_{1}$ $\left(E_{C}-0.252 \mathrm{eV}\right), E_{2}\left(E_{C}-0.53 \mathrm{eV}\right), E_{3}\left(E_{C}-0.69 \mathrm{eV}\right), E_{4}\left(E_{C}-0.65\right.$ $\mathrm{eV}), \mathrm{E}_{5}\left(\mathrm{E}_{\mathrm{C}}-1.4 \mathrm{eV}\right)$, and $\mathrm{E}_{6}\left(\mathrm{E}_{\mathrm{C}}-1.55 \mathrm{eV}\right)$. Among them, trap $\mathrm{E}_{4}$ and trap $\mathrm{E}_{6}$ which has not been previous reported is suggested to be introduced by the polishing process. The capture cross-section of trap E1, E2, E4 was determined by using the filling pulse width technique. From the behavior of the DLTS signal vs the filling pulse width plot, it is suggested that these traps probably are associated with point defects. These capture cross-sections were temperature independent.

Paper 2: Electron-irradiation-induced defects in bulk GaN grown by halide vapor phase epitaxy were investigated by deep level transient spectroscopy. The sample was irradiated by $2 \mathrm{MeV}$ electron at a fluence of $1 \times 10^{14} \mathrm{~cm}^{2}$. The traps, labeled D2 $\left(\mathrm{E}_{\mathrm{C}}-0.24 \mathrm{eV}\right), \mathrm{D} 3\left(\mathrm{E}_{\mathrm{C}}-0.60\right.$ $\mathrm{eV}), \mathrm{D} 4\left(\mathrm{E}_{\mathrm{C}}-0.69 \mathrm{eV}\right), \mathrm{D} 5\left(\mathrm{E}_{\mathrm{C}}-0.96 \mathrm{eV}\right), \mathrm{D} 7\left(\mathrm{E}_{\mathrm{C}}-1.19 \mathrm{eV}\right)$, and D8, were observed before performing irradiation. Three electron-irradiationinduced traps, labeled as D1 (EC-0.12 eV), D5I (EC-0.89 eV), and D6 $(\mathrm{EC}-1.14 \mathrm{eV})$, were observed. Among the three irradiation-induced traps, the trap D1 has previously been reported few times and suggested to be associated with the nitrogen vacancy. The D5I and D6 centers are suggested to be related to primary intrinsic defects due to their the annealing behavior.

Paper 3: A thick GaN grown by halide vapor phase epitaxy was irradiated by $2 \mathrm{MeV}$ at a fluence of $5 \times 10^{14} \mathrm{~cm}^{2}$ and then characterized by deep level transient spectroscopy. The paper focused on determining the capture cross-section and its temperature dependence of electronirradiation-induced deep levels by the filling pulse method. After irradiation, four deep trap levels, labelled ET1 $\left(\mathrm{E}_{\mathrm{C}}-0.178 \mathrm{eV}\right), \mathrm{ET} 2\left(\mathrm{E}_{\mathrm{C}}-\right.$ $0.181 \mathrm{eV})$, ET3 $\left(\mathrm{E}_{\mathrm{C}}-0.256 \mathrm{eV}\right)$ and ET5 were observed. After annealing at $650 \mathrm{~K}$ for 2 hours, only two deep levels ET1 and ET4 were detected. The temperature behavior of the deep level ET1 showed that the capturing process is probably related to the multiphonon process whereas the capture cross-section of the deep levels of ET2 and ET3 is not dependent on the temperature. 


\section{Bibliography}

[1] H. P. Maruska and J. J. Tietjen, "The preparation and properties of vapor-deposited single crystalline GaN," Appl. Phys. Lett., vol. 15, no. 10, p. 327, 1969.

[2] I. Vurgaftman and J. R. Meyer, "Band parameters for nitrogencontaining semiconductors," J. Appl. Phys., vol. 94, no. 6, p. 3675, 2003.

[3] S. P. Denbaars, "Gallium-nitride-based materials for blue to ultraviolet optoelectronics devices," Proc. IEEE, vol. 85, no. 11, pp. 1740-1749, 1997.

[4] S. Nakamura, M. Senoh, S. Nagahama, N. Iwasa, T. Yamada, T. M.- Sushita, H. Kiyoku, and Y. Sugimoto, "InGaN-Based MultiQuantum-Well-Structure Laser Diodes.pdf.” p. L74, 1996.

[5] S. Nakamura, T. Mukai, and M. Senod, "Candela-class highbrightness InGaN/AlGaN double-heterostructure blue-lightemitting diodes," Appl. Phys. Lett., vol. 64, p. 1687, 1994.

[6] I. Akasaki, "GaN-Based p-n Junction Blue-Light-Emitting Devices," Proc. IEEE, vol. 101, no. 10, pp. 2200-2210, Oct. 2013.

[7] S. Nakamura, M. Senoh, N. Iwasa, S. Nagahama, T. Yamada, and T. Mukai, "Superbright Green InGaN Single-Quantum-WellStructure Light-Emitting Diodes.pdf," Jpn. J. Appl. Phys., vol. 34, pp. L1332-L1335, 1995.

[8] S. J. Pearton, J. C. Zolper, R. J. Shul, and F. Ren, "GaN: Processing, defects, and devices," J. Appl. Phys., vol. 86, no. 1, p. $1,1999$.

[9] Z. M. Zhao, R. L. Jiang, P. Chen, D. J. Xi, Z. Y. Luo, R. Zhang, B. Shen, Z. Z. Chen, and Y. D. Zheng, "Metal-semiconductormetal GaN ultraviolet photodetectors on Si(111)," Appl. Phys. Lett., vol. 77, no. 3, p. 444, 2000. 
[10] J. C. Carrano, T. Li, D. L. Brown, P. a. Grudowski, C. J. Eiting, R. D. Dupuis, and J. C. Campbell, "Very high-speed metalsemiconductor-metal ultraviolet photodetectors fabricated on GaN," Appl. Phys. Lett., vol. 73, no. 17, p. 2405, 1998.

[11] D. Walker, E. Monroy, P. Kung, J. Wu, M. Hamilton, F. J. Sanchez, J. Diaz, and M. Razeghi, "High-speed, low-noise metal-semiconductor-metal ultraviolet photodetectors based on GaN," Appl. Phys. Lett., vol. 74, no. 5, p. 762, 1999.

[12] O. Jani, I. Ferguson, C. Honsberg, and S. Kurtz, "Design and characterization of GaNhnaN solar cells," Appl. Phys. Lett., vol. 91, no. 13, p. 132117, 2007.

[13] D.-J. Seo, J.-P. Shim, S.-B. Choi, T. H. Seo, E.-K. Suh, and D.-S. Lee, "Efficiency improvement in InGaN-based solar cells by indium tin oxide nano dots covered with ITO films.," Opt. Express, vol. 20, no. S6, pp. A991-A996, Dec. 2012.

[14] R. Horng, S. Lin, Y. Tsai, M. Chu, W. Liao, M. Wu, R. Lin, and Y. Lu, "Improved Conversion Efficiency of GaN/InGaN ThinFilm Solar Cells," IEEE Electron Device Lett., vol. 30, no. 7, pp. 724-726, 2009.

[15] Q. Chen, M. Asif Khan, J. W. Yang, C. J. Sun, M. S. Shur, and H. Park, "High transconductance heterostructure field-effect transistors based on AlGaN/GaN," Appl. Phys. Lett., vol. 69, no. 6, p. 794, 1996.

[16] M. Yanagihara, Y. Uemoto, T. Ueda, T. Tanaka, and D. Ueda, "Recent advances in GaN transistors for future emerging applications," Phys. Status Solidi, vol. 206, no. 6, pp. 1221-1227, Jun. 2009.

[17] B. J. Baliga, "Gallium nitride devices for power electronic applications," Semicond. Sci. Technol., vol. 28, no. 7, p. 074011, Jul. 2013. 
[18] T. P. Chow, "High-voltage $\mathrm{SiC}$ and $\mathrm{GaN}$ power devices," Microelectron. Eng., vol. 83, no. 1, pp. 112-122, Jan. 2006.

[19] Y.-F. Wu, D. Kapolnek, J. P. Ibbetson, P. Parikh, B. P. Keller, and U. K. Mishra, "Very-high power density AlGaN/GaN HEMTs," IEEE Trans. Electron Devices, vol. 48, no. 3, pp. 586590, Mar. 2001.

[20] T. Uesugi and T. Kachi, "GaN Power Switching Devices for Automotive Applications," CS MANTECH Conf., no. Paper 2.1, 2009.

[21] X. H. Wu, D. Kapolnek, E. J. Tarsa, B. Heying, S. Keller, B. P. Keller, U. K. Mishra, S. P. DenBaars, and J. S. Speck, "Nucleation layer evolution in metal-organic chemical vapor deposition grown GaN," Appl. Phys. Lett., vol. 68, no. 10, p. 1371, 1996.

[22] B. Heying, R. Averbeck, L. F. Chen, E. Haus, H. Riechert, and J. S. Speck, "Control of GaN surface morphologies using plasmaassisted molecular beam epitaxy," J. Appl. Phys., vol. 88, no. 4, p. $1855,2000$.

[23] C. Hemmingsson and G. Pozina, "Optimization of low temperature $\mathrm{GaN}$ buffer layers for halide vapor phase epitaxy growth of bulk GaN," J. Cryst. Growth, vol. 366, pp. 61-66, Mar. 2013.

[24] C. Hemmingsson, M. Boota, R. Rahmatalla, M. Junaid, G. Pozina, J. Birch, and B. Monemar, "Growth and characterization of thick GaN layers grown by halide vapour phase epitaxy on lattice-matched AlInN templates," J. Cryst. Growth, vol. 311, no. 2, pp. 292-297, Jan. 2009.

[25] C. Hemmingsson, P. P. Paskov, G. Pozina, M. Heuken, B. Schineller, and B. Monemar, "Growth of bulk GaN in a vertical hydride vapour phase epitaxy reactor," Superlattices Microstruct., vol. 40, no. 4-6, pp. 205-213, Oct. 2006. 
[26] R. Madar, G. Jacob, J. Hallais, and R. Fruchart, "High pressure solution growth of GaN," J. Cryst. Growth, vol. 31, p. 197, 1975.

[27] S. Porowski, "High pressure growth of GaN - new prospects for blue lasers," J. Cryst. Growth, vol. 166, pp. 583-589, 1996.

[28] H. Yamane, M. Shimada, S. J. Clarke, and F. J. Disalvo, "Preparation of GaN Single Crystals Using a Na Flux," Chem. Mater., vol. 1896, no. 1, pp. 413-416, 1997.

[29] Y. Mori, M. Imade, M. Maruyama, and M. Yoshimura, "Growth of GaN Crystals by Na Flux Method," ECS J. Solid State Sci. Technol., vol. 2, no. 8, pp. N3068-N3071, Jul. 2013.

[30] B. Wang and M. J. Callahan, "Ammonothermal Synthesis of IIINitride Crystals 2006," Cryst. Growth Des., vol. 6, pp. 12271246, 2006.

[31] M. E. Levinshtein, S. L. Rumyantsev, and M. S. Shur, Properties of Advanced Semiconductor Materials: GaN, AlN, InN, BN, and SiGe. New York: John Wiley and Sons, 2001, pp. 1-30.

[32] "http://www.ioffe.ru/SVA/NSM/Semicond/Si/index.html." .

[33] "http://www.ioffe.ru/SVA/NSM/Semicond/GaAs/index.html.”.

[34] "http://www.ioffe.ru/SVA/NSM/Semicond/AlN/index.html.".

[35] "http://www.ioffe.ru/SVA/NSM/Semicond/InN/index.html.".

[36] "http://www.ioffe.ru/SVA/NSM/Semicond/SiC/index.html.”.

[37] "http://www.ioffe.ru/SVA/NSM/Semicond/GaN/index.html.” .

[38] "http://www.ioffe.ru/SVA/NSM/Semicond/Diamond/index.html"

[39] M. Aoki, H. Yamane, M. Shimada, and S. Sarayama, "GaN single crystal growth using high-purity $\mathrm{Na}$ as a flux," J. Cryst. Growth, vol. 242, pp. 70-76, 2002. 
[40] H. Amano, M. Kito, K. Hiramatsu, and I. Akasaki, "P-Type Conduction in Mg-Doped GaN Treated with Low-Energy Electron Beam Irradiation ( LEEBI )," Jpn. J. Appl. Phys., vol. 28, pp. L2112-L2114, 1989.

[41] S. Fischer, C. Wetzel, E. E. Haller, and B. K. Meyer, "doping in GaN-acceptor binding energies," Appl. Phys. Lett., vol. 67, pp. 1298-1300, 1995.

[42] S. Strite and H. Morkoç, "GaN, AlN, and InN: A review," J. Vac. Sci. Technol. B Microelectron. Nanom. Struct., vol. 10, no. 4, p. 1237, Jul. 1992.

[43] W. Götz, N. M. Johnson, J. Walker, D. P. Bour, and R. a. Street, "Activation of acceptors in Mg-doped $\mathrm{GaN}$ grown by metalorganic chemical vapor deposition," Appl. Phys. Lett., vol. 68, no. 5, p. 667, 1996.

[44] E. Letts, T. Hashimoto, S. Hoff, D. Key, K. Male, and M. Michaels, "Development of GaN wafers via the ammonothermal method," J. Cryst. Growth, vol. 403, pp. 3-6, Oct. 2014.

[45] D. Johnstone, S. Doğan, J. Leach, Y. T. Moon, Y. Fu, Y. Hu, and H. Morkoç, "Thermal stability of electron traps in GaN grown by metalorganic chemical vapor deposition," Appl. Phys. Lett., vol. 85, no. 18, p. 4058, 2004.

[46] W. I. Lee, T. C. Huang, J. D. Guo, and M. S. Feng, "Effects of column III alkyl sources on deep levels in GaN grown by organometallic vapor phase epitaxy," Appl. Phys. Lett., vol. 67, no. 12 , p. 1721, 1995.

[47] Y. Tokuda, Y. Matsuoka, H. Ueda, O. Ishiguro, N. Soejima, and T. Kachi, "DLTS study of n-type GaN grown by MOCVD on GaN substrates," Superlattices Microstruct., vol. 40, no. 4-6, pp. 268-273, Oct. 2006.

[48] P. Kamyczek, E. Placzek-Popko, Z. R. Zytkiewicz, E. Zielony, and Z. Gumienny, "Deep traps in n-type GaN epilayers grown by 
plasma assisted molecular beam epitaxy," J. Appl. Phys., vol. 115, no. 2, p. 023102, Jan. 2014.

[49] C. D. Wang, L. S. Yu, S. S. Lau, E. T. Yu, and W. Kim, "Deep level defects in n-type GaN grown by molecular beam epitaxy," Appl. Phys. Lett., vol. 72, no. 10, pp. 1211-1213, 1998.

[50] H. Ashraf, M. I. Arshad, S. M. Faraz, Q. Wahab, P. R. Hageman, and M. Asghar, "Study of electric field enhanced emission rates of an electron trap in n-type $\mathrm{GaN}$ grown by hydride vapor phase epitaxy," J. Appl. Phys., vol. 108, no. 10, p. 103708, 2010.

[51] P. Hacke, T. Detchprohm, K. Hiramatsu, N. Sawaki, K. Tadatomo, and K. Miyake, "Analysis of deep levels in n-type GaN by transient capacitance methods," J. Appl. Phys., vol. 76, no. 1, p. 304, 1994.

[52] L. Wu, W. E. Meyer, F. D. Auret, and M. Hayes, "Biasdependent deep level in HVPE n-GaN," Phys. B Condens. Matter, vol. 340-342, pp. 475-478, Dec. 2003.

[53] F. D. Auret, S. a. Goodman, F. K. Koschnick, J.-M. Spaeth, B. Beaumont, and P. Gibart, "Electrical characterization of two deep electron traps introduced in epitaxially grown $\mathrm{n}-\mathrm{GaN}$ during $\mathrm{He}-$ ion irradiation," Appl. Phys. Lett., vol. 73, no. 25, p. 3745, 1998.

[54] F. D. Auret, S. a. Goodman, F. K. Koschnick, J.-M. Spaeth, B. Beaumont, and P. Gibart, "Electrical characterization of two deep electron traps introduced in epitaxially grown $\mathrm{n}-\mathrm{GaN}$ during Heion irradiation," Appl. Phys. Lett., vol. 73, no. 25, p. 3745, 1998.

[55] V. N. Brudnyi, S. S. Verevkin, a. V. Govorkov, V. S. Ermakov, N. G. Kolin, a. V. Korulin, a. Y. Polyakov, and N. B. Smirnov, "Electronic properties and deep traps in electron-irradiated nGaN," Semiconductors, vol. 46, no. 4, pp. 433-439, Apr. 2012.

[56] A. Castaldini, A. Cavallini, and L. Polenta, "Deep levels and irradiation effects in n-GaN," J. Phys. Condens. Matter, vol. 12, pp. 10161-10167, 2000. 
[57] S. A. Goodman, F. D. Auret, M. J. Legodi, B. Beaumont, and P. Gibart, "Characterization of electron-irradiated n-GaN," Appl. Phys. Lett., vol. 78, no. 24, p. 3815, 2001.

[58] D. U. Lee, E. K. Kim, B. C. Lee, and D. K. Oh, "Characterization of electron irradiated GaN n+-p diode," Thin Solid Films, vol. 516, no. 11, pp. 3482-3485, Apr. 2008.

[59] H. Nykänen, S. Suihkonen, L. Kilanski, M. Sopanen, and F. Tuomisto, "Low energy electron beam induced vacancy activation in GaN," Appl. Phys. Lett., vol. 100, no. 12, p. 122105, 2012.

[60] L. Polenta, Z.-Q. Fang, and D. C. Look, "On the main irradiationinduced defect in GaN," Appl. Phys. Lett., vol. 76, no. 15, p. 2086, 2000.

[61] F. Tuomisto, V. Ranki, D. Look, and G. Farlow, "Introduction and recovery of $\mathrm{Ga}$ and $\mathrm{N}$ sublattice defects in electron-irradiated GaN," Phys. Rev. B, vol. 76, no. 16, p. 165207, Oct. 2007.

[62] S. . Goodman, F. . Auret, G. Myburg, M. . Legodi, P. Gibart, and B. Beaumont, "Deep levels introduced in $n-G a N$ grown by the ELOG technique by high-energy electron irradiation," Mater. Sci. Eng. B, vol. 82, no. 1-3, pp. 95-97, May 2001.

[63] Z.-Q. Fang, J. W. Hemsky, D. C. Look, and M. P. Mack, "Electron-irradiation-induced deep level in n-type GaN," Appl. Phys. Lett., vol. 72, no. 4, p. 448, 1998.

[64] H. Nykänen, S. Suihkonen, L. Kilanski, M. Sopanen, and F. Tuomisto, "Low energy electron beam induced vacancy activation in GaN," Appl. Phys. Lett., vol. 100, no. 12, p. 122105, 2012.

[65] A. Y. Polyakov, I.-H. Lee, N. B. Smirnov, A. V. Govorkov, E. A. Kozhukhova, N. G. Kolin, A. V. Korulin, V. M. Boiko, and S. J. Pearton, "10 MeV electrons irradiation effects in variously doped n-GaN,” J. Appl. Phys., vol. 109, no. 12, p. 123703, 2011. 
[66] S. C. Binari, H. B. Dietrich, G. Kelner, L. B. Rowland, K. Doverspike, and D. K. Wickenden, "H, He, and $\mathrm{N}$ implant isolation of n-type GaN," J. Appl. Phys., vol. 78, no. 5, p. 3008, 1995.

[67] L. Ha, D. U. Lee, J. S. Kim, E. K. Kim, B. C. Lee, D. K. Oh, S.B. Bae, and K.-S. Lee, "Study on Defect States in GaN Epilayer Induced by Irradiation of High-Energy Electrons," Jpn. J. Appl. Phys., vol. 47, no. 8, pp. 6867-6869, Aug. 2008.

[68] D. V. Lang, "Deep level transient spectroscopy: A new method to characterize traps in semiconductors.pdf," J. Appl. Phys., vol. 45, p. 3023, 1974.

[69] T. T. Duc, G. Pozina, E. Janzén, and C. Hemmingsson, "Investigation of deep levels in bulk GaN material grown by halide vapor phase epitaxy," J. Appl. Phys., vol. 114, no. 15, p. 153702, 2013.

[70] T. T. Duc, G. Pozina, N. T. Son, E. Janzén, T. Ohshima, and C. Hemmingsson, "Radiation-induced defects in GaN bulk grown by halide vapor phase epitaxy," Appl. Phys. Lett., vol. 105, no. 10, p. 102103, Sep. 2014.

[71] T. Lei, M. Fanciulli, R. J. Molnar, T. D. Moustakas, R. J. Graham, and J. Scanlon, "Epitaxial growth of zinc blende and wurtzitic gallium nitride thin films on (001) silicon," Appl. Phys. Lett., vol. 59, no. 8, p. 944, 1991.

[72] E. K. Sichel and J. I. Pankove, "Thermal conductivity of GaN, 25-360 K," J. Phys. Chem. Solids, vol. 38, no. 3, p. 330, 1977.

[73] C.-Y. Luo, H. Marchand, D. R. Clarke, and S. P. DenBaars, "Thermal conductivity of lateral epitaxial overgrown GaN films," Appl. Phys. Lett., vol. 75, no. 26, p. 4151, 1999.

[74] A. Jeżowski, B. A. Danilchenko, M. Boćkowski, I. Grzegory, S. Krukowski, T. Suski, and T. Paszkiewicz, "Thermal conductivity 
of GaN crystals in 4.2-300 K range," Solid State Commun., vol. 128, no. 2-3, pp. 69-73, Oct. 2003.

[75] D. I. Florescu, V. M. Asnin, F. H. Pollak, R. J. Molnar, and C. E. C. Wood, "High spatial resolution thermal conductivity and Raman spectroscopy investigation of hydride vapor phase epitaxy grown n-GaN/sapphire (0001): Doping dependence," J. Appl. Phys., vol. 88, no. 6, p. 3295, 2000.

[76] D. I. Florescu, V. M. Asnin, F. H. Pollak, A. M. Jones, J. C. Ramer, M. J. Schurman, and I. Ferguson, "Thermal conductivity of fully and partially coalesced lateral epitaxial overgrown GaN/sapphire (0001) by scanning thermal microscopy," Appl. Phys. Lett., vol. 77, no. 10, p. 1464, 2000.

[77] H. Shibata, Y. Waseda, H. Ohta, K. Kiyomi, K. Shimoyama, K. Fujito, H. Nagaoka, Y. Kagamitani, R. Simura, and T. Fukuda, "High Thermal Conductivity of Gallium Nitride $(\mathrm{GaN})$ Crystals Grown by HVPE Process," Mater. Trans., vol. 48, no. 10, pp. 2782-2786, 2007.

[78] G. A. Slack, L. J. Schowalter, D. Morelli, and J. A. Freitas, "Some effects of oxygen impurities on AlN and GaN," J. Cryst. Growth, vol. 246, no. 3-4, pp. 287-298, Dec. 2002.

[79] A. Witek, "Some aspects of thermal conductivity of isotopically pure diamond-a comparison with nitrides," Diam. Relat. Mater., vol. 7, no. 7, pp. 962-964, Jul. 1998.

[80] J. I. Pankove, "Electrolytic Etching of GaN," J. Electrochem. Soc., vol. 119, no. 8, p. 1118, 1972.

[81] C. B. Vartuli, S. J. Pearton, C. R. Abernathy, J. D. MacKenzie, F. Ren, J. C. Zolper, and R. J. Shul, "Wet chemical etching survey of III-nitrides," Solid. State. Electron., vol. 41, no. 12, pp. 19471951, 1997. 
[82] C. H. Ko, Y. K. Su, S. J. Chang, W. H. Lan, J. Webb, M. C. Tu, and Y. T. Cherng, "Photo-enhanced chemical wet etching of GaN,” Mater. Sci. Eng. B, vol. 96, no. 1, pp. 43-47, Oct. 2002.

[83] T. L. Chu, "Gallium Nitride Films," J. Electrochem. Soc., vol. 118, no. 7, p. 1200, 1971.

[84] J. R. Mileham, "Patterning of AlN, InN, and GaN in KOH-based solutions," J. Vac. Sci. Technol. A Vacuum, Surfaces, Film., vol. 14, no. 3, p. 836, May 1996.

[85] D. Zhuang and J. H. Edgar, "Wet etching of GaN, AlN, and SiC: a review," Mater. Sci. Eng. R Reports, vol. 48, no. 1, pp. 1-46, Jan. 2005.

[86] H. Morkoç, "General Properties of Nitrides," in Handbook of nitride semiconductors and devices. Vol 1., vol. 1, 2008, pp. 1129.

[87] T. Palacios, F. Calle, M. Varela, C. Ballesteros, E. Monroy, F. B. Naranjo, M. A. Sánchez-García, E. Calleja, and E. Muñoz, "Wet etching of $\mathrm{GaN}$ grown by molecular beam epitaxy on $\mathrm{Si}(111)$," Semicond. Sci. Technol., vol. 15, no. 10, pp. 996-1000, Oct. 2000.

[88] D. A. Stocker, E. F. Schubert, and J. M. Redwing, "Crystallographic wet chemical etching of GaN," Appl. Phys. Lett., vol. 73, no. 18, p. 2654, 1998.

[89] A. Shintani and S. Minagawa, "Etching of GaN Using Phosphoric Acid," J. Electrochem. Soc., vol. 123, pp. 706-713, 1976.

[90] H. M. Manasevit, F. M. Erdmann, and W. I. Simpson, "The Use of Metalorganics in the Preparation of Semiconductor Materials," J. Electrochem. Soc., vol. 118, no. 11, p. 1864, 1971. 
[91] H. Amano, N. Sawaki, I. Akasaki, and Y. Toyoda, "Metalorganic vapor phase epitaxial growth of a high quality GaN film using an AlN buffer layer," Appl. Phys. Lett., vol. 48, no. 5, p. 353, 1986.

[92] B. Łucznik, B. Pastuszka, I. Grzegory, M. Boćkowski, G. Kamler, E. Litwin-Staszewska, and S. Porowski, "Deposition of thick GaN layers by HVPE on the pressure grown $\mathrm{GaN}$ substrates," J. Cryst. Growth, vol. 281, no. 1, pp. 38-46, Jul. 2005.

[93] C. Hemmingsson, B. Monemar, Y. Kumagai, and A. Koukitu, "Growth of III-Nitrides with Halide Vapor Phase Epitaxy (HVPE)," in Springer Handbook of Crystal Growth, vol. 2, no. 1, 2010, pp. 869-896.

[94] V. S. Ban, "Mass spectrometric and thermodynamic studies of the CVD of some III-V compounds," J. Cryst. Growth, vol. 17, pp. 19-30, 1972.

[95] P. A. Denis and K. Balasubramanian, "Spectroscopic constants and potential energy curves of gallium nitride $(\mathrm{GaN})$ and ions: GaN+ and GaN-," Chem. Phys. Lett., vol. 423, no. 1-3, pp. 247253, May 2006.

[96] D. Tzeli and A. A. Tsekouras, "The electron affinity of gallium nitride $(\mathrm{GaN})$ and digallium nitride $(\mathrm{GaNGa})$ : the importance of the basis set superposition error in strongly bound systems.," $J$. Chem. Phys., vol. 128, no. 14, p. 144103, Apr. 2008.

[97] A. C. Schmitz, A. T. Ping, M. A. Khan, Q. Chen, J. W. Yang, and I. Adesida, "Schottky barrier properties of various metals on ntype GaN," Semicond. Sci. Technol., vol. 11, no. 10, pp. 14641467, Oct. 1996.

[98] A. C. Schmitz, A. T. Ping, M. A. Khan, Q. Chen, J. W. Yang, and I. Adesida, "Metal Contacts to n-Type GaN," J. Electron. Mater., vol. 27, pp. 255-260, 1998. 
[99] D. R. Lide, CRC Handbook of Chemistry and Physics, Internet Version 2005, 〈http://www.hbcpnetbase.com>. 2005, pp. 12124.

[100] V. Zeghbroeck, Principles of Semiconductor Devices. 2004.

[101] S. M. Sze and K. K. Ng, Physics of semiconductor devices. 2006.

[102] M. O. Alade, "High Temperature Electronic Properties of a Microwave Frequency Sensor - GaN Schottky Diode," Adv. Phys. Theor. Appl., vol. 15, pp. 47-53, 2013.

[103] P. Blood and J. W. Orton, The Electrical Characterization of Semiconductors: Majority Carriers and Electron States. Academic Press, 1992.

[104] R. N. Hall, "Electron-Hole Recombination in Germanium," Phys. Rev., vol. 87, p. 387, 1952.

[105] W. Shockley and W. T. Read, "Statistics of the Recombinations of Holes and Electrons," Phys. Rev., vol. 87, pp. 835-842, 1952.

[106] C. Kittel, "Semiconductor crystals," in Introduction of Solid State Physics, John Wiley \& Sons, 2005, p. 206.

[107] D. K. Schroder, Semiconductor material and device characterization. New Jersey: John Wiley \& Sons, 2006, p. 275.

[108] C. H. Henry and D. V. Lang, "Nonradiative capture and recombination by multiphonon emission in GaAs and GaP," Phys. Rev. B, vol. 15, pp. 989-1016, 1977.

[109] J. Criado, A. Gomez, E. Calleja, and E. Muñoz, "Novel method to determine capture crosssection activation energies by deeplevel transient spectroscopy techniques," Appl. Phys. Lett., vol. 52, p. 660, 1988.

[110] E. PŁaczek-Popko, J. Trzmiel, E. Zielony, S. Grzanka, R. Czernecki, and T. Suski, "Deep level transient spectroscopy 
signatures of majority traps in GaN $\mathrm{p}-\mathrm{n}$ diodes grown by metalorganic vapor-phase epitaxy technique on GaN substrates," Phys. B Condens. Matter, vol. 404, no. 23-24, pp. 4889-4891, Dec. 2009.

[111] D. Pons, "Accurate determination of the free carrier capture kinetics of deep traps by space-charge methods," J. Appl. Phys., vol. 55 , no. 10 , p. $3644,1984$.

[112] T. Wosiński, "Evidence for the electron traps at dislocations in GaAs crystals," J. Appl. Phys., vol. 65, no. 4, p. 1566, 1989.

[113] S. D. Brotherton, "The width of the non-steady state transition region in deep level impurity measurements," Solid. State. Electron., vol. 26, no. 10, pp. 987-990, Oct. 1983.

[114] M. C. Chen, D. V. Lang, W. C. Dautremont-Smith, a. M. Sergent, and J. P. Harbison, "Effects of leakage current on deep level transient spectroscopy," Appl. Phys. Lett., vol. 44, no. 8, p. 790, 1984.

[115] “http://www.tf.uni-kiel.de/matwis/amat/def_en/." . 


\section{Included Papers}

The articles associated with this thesis have been removed for copyright reasons. For more details about these see:

http://urn.kb.se/resolve?urn=urn:nbn:se:liu:diva-112262 